\title{
Modelling the diurnal cycle of deep precipitating convection over land with cloud-resolving models and single-column models
}

\author{
By F. GUICHARD ${ }^{1 *}$, J. C. PETCH ${ }^{2}$, J.-L. REDELSPERGER ${ }^{1}$, P. BECHTOLD ${ }^{3}$, J.-P. CHABOUREAU ${ }^{1,4}$, \\ S. CHEINET ${ }^{5}$, W. GRABOWSKI ${ }^{6}$, H. GRENIER ${ }^{1}$, C. G. JONES ${ }^{7}$, M. KÖHLER ${ }^{3}$, J.-M. PIRIOU ${ }^{1}$, \\ R. TAILLEUX ${ }^{5}$ and M. TOMASINI ${ }^{1}$ \\ ${ }^{1}$ CNRM/GAME, Toulouse, France \\ ${ }^{2}$ Met Office, Exeter, UK \\ ${ }^{3}$ European Centre for Medium-Range Weather Forecasts, Reading, UK \\ ${ }^{4}$ Laboratoire d'aérologie, Paris, France \\ ${ }^{5}$ Laboratoire de Météorologie Dynamique, Paris, France \\ ${ }^{6}$ National Center for Atmospheric Research, Boulder, USA \\ ${ }^{7}$ Swedish Meteorological and Hydrological Institute, Rossby Center, Norrköping, Sweden
}

\section{SUMMARY}

An idealized case-study has been designed to investigate the modelling of the diurnal cycle of deep precipitating convection over land. A simulation of this case was performed by seven single-column models (SCMs) and three cloud-resolving models (CRMs). Within this framework, a quick onset of convective rainfall is found in most SCMs, consistent with the results from general-circulation models. In contrast, CRMs do not predict rainfall before noon. A joint analysis of the results provided by both types of model indicates that convection occurs too early in most SCMs, due to crude triggering criteria and quick onsets of convective precipitation. In the CRMs, the first clouds appear before noon, but surface rainfall is delayed by a few hours to several hours. This intermediate stage, missing in all SCMs except for one, is characterized by a gradual moistening of the free troposphere and an increase of cloud-top height. Later on, convective downdraughts efficiently cool and dry the boundary layer (BL) in the CRMs. This feature is also absent in most SCMs, which tend to adjust towards more unstable states, with moister (and often more cloudy) low levels and a drier free atmosphere. This common behaviour of most SCMs with respect to deep moist convective processes occurs even though each SCM simulates a different diurnal cycle of the BL and atmospheric stability. The scatter among the SCMs results from the wide variety of representations of BL turbulence and moist convection in these models. Greater consistency is found among the CRMs, despite some differences in their representation of the daytime BL growth, which are linked to their parametrizations of BL turbulence and/or resolution.

KEYWORDS: Cloud parametrization Moisture Stability Transition regimes

\section{INTRODUCTION}

'Convective organization' refers to the various space and time scales of convective phenomena, and frequently to their degree of mesoscale organization. In this respect, the diurnal cycle of solar radiation represents an efficient and widespread mode of convective organization. Its magnitude is particularly large over land in summer (e.g. Wallace 1975; Duvel 1989; Dai et al. 1999) as a result of stronger daytime boundarylayer heating during this season. In this situation, precipitating convection typically takes place during the afternoon and/or evening. This broad picture is further modulated by regional features, such as land-sea and mountain-valley breezes (Garreaud and Wallace 1997; Yang and Slingo 2001; Liberti et al. 2001) and meteorological regimes (e.g. Rickenbach et al. 2002). Some areas are also characterized by complex diurnal cycles of rainfall as a result of the propagation of mesoscale convective systems over hundreds of kilometres, or even very large convective episodes initially triggered by daytime heating, as reported by Carbone et al. (2002).

In addition to its importance for weather forecasts, this temporal organization is not neutral with respect to the energy and water budgets on a local scale, but also at

\footnotetext{
* Corresponding author: CNRM/GAME (CNRS and Météo-France), 42 avenue Coriolis, 31057 Toulouse Cedex, France. e-mail: francoise.guichard@meteo.fr
} 
large scale (Bergman and Salby 1997). Indeed, convectively generated clouds strongly interact with both solar and thermal infrared radiative fluxes, but in drastically different ways. At night, clouds contribute to the greenhouse effect by efficiently trapping thermal infrared radiation, so that night-time surface temperature is warmer under cloudy conditions. During the day, the reflection of insolation generally dominates over the greenhouse effect, leading to an opposite effect on surface temperature. Therefore, it is necessary to predict correctly the time of day during which these clouds are present in order to get an accurate radiative budget, both at the top of the atmosphere and at the surface. Clouds also strongly modulate the magnitude of surface heat fluxes (sensible plus latent) through their impact on the net radiative fluxes at the surface. Similarly, the magnitude of their impact on the surface heat flux also depends on the diurnal timing of clouds, because of the large daily variation of surface heat fluxes over land. From a broader perspective, the $1 \mathrm{~K}$ global warming that occurred during the last century shows a pronounced diurnal structure (IPCC 2001), the night-time warming being much stronger (possibly because of higher cloud cover at night, see for example Dai et al. (1997)). Modifications of the diurnal cycle of rainfall have even been reported (Dai 1999). These findings suggest that a proper simulation of the actual diurnal cycle of convection is also required in order to capture its possible fluctuations in the context of climate sensitivities.

The nature of the problem is not the same over the land and over the ocean. Over land, the diurnal cycle of deep convection is strongly linked to daytime boundary-layer heating, whereas over the ocean the diurnal variations of the sea surface temperature (SST) and the boundary layer are much weaker (in fact, there is no consensus towards a theory explaining the phenomenon over ocean yet)—see Xu and Randall (1995) and Liu and Moncrieff (1998) for a review. However, several recent studies have shown that it is difficult for general-circulation models (GCMs) to capture the diurnal cycle of deep convection, in terms of both magnitude and phase, over the land as well as over the ocean (Dai et al. 1999; Lin et al. 2000; Royer et al. 2000; Yang and Slingo 2001; Betts and Jakob 2002a). Interestingly, all these studies detected a time lag in the diurnal cycle of deep convection simulated by large-scale models, with convective rainfall occurring too early during daytime compared with observations. A similar finding was made during the course of EUROCS* for the large-scale models involved in the project $\dagger$. All these studies show that an improvement in the diurnal cycle of convection simulated by largescale models is required (Bechtold et al. 2004). To do so, it is necessary to identify the causes of this time lag.

The aim of the present study was first to design a simple framework, or case-study, that allows us to address this issue, and then to investigate the reasons behind this common weakness of large-scale models. Simulations of this case have been jointly performed by single-column models (SCMs) and cloud-resolving models (CRMs), i.e. with the same initial conditions and large-scale forcing adopted in both types of model, this information being derived from observations. An SCM is a one-dimensional (1D) version of a large-scale model, including the same subgrid-scale parametrizations. A number of recent studies have shown the usefulness of such a strictly controlled SCM framework, that efficiently isolates the parametrizations from the complex feedback loops involved in three-dimensional (3D) large-scale models. On the other hand, a CRM is a finer-scale model, with a horizontal resolution of the order of a kilometre. CRMs

\footnotetext{
${ }^{*}$ EUROpean Cloud Systems project.

$\dagger$ The reader is referred to http://www.cnrm.meteo.fr/gcss/EUROCS/deepdiurnland.html where additional documentation on this issue is available.
} 
have been widely used and validated during the past twenty years and, more recently, intercompared (Redelsperger et al. 2000; Xu et al. 2002). Therefore, CRMs are expected to simulate precipitating systems better than SCMs with parametrized convection, thus providing guidance for improving the parametrizations of these fine-scale phenomena.

Previous intercomparisons of such deep convective systems simulated by CRMs and SCMs have focused on the characteristics of mature squall lines (Redelsperger et al. 2000; Bechtold et al. 2000) and on the main features of deep convective systems strongly forced by large-scale advection (Xu et al. 2002; Xie et al. 2002; Krueger 1997). In contrast, the present study focuses on a transient regime that does not involve significant large-scale forcing. Therefore, we are interested here in the factors involved in the development - and the suppression - of deep convection. The following section presents the case-study set-up. Section 3 briefly summarizes the main characteristics of the models involved. Results are presented and discussed in section 4, and the paper concludes with section 5 .

\section{THE DIURNAL-CYCLE CASE: SiMULATION SET-UP}

The aim of this study is to analyse the response of CRMs and SCMs to the diurnal cycle of boundary-layer heating over land in summer for a simple, but not unrealistic, situation. Therefore, the design of this idealized case-study has been derived from a continental situation, the GEWEX (Global Energy and Water-cycle EXperiment) cloud system study (GCSS) working group-4 (WG-4) Case 3 (Xu et al. 2002; Xie et al. 2002). This case was the first GCSS attempt to assess explicit simulations of deep convection over land, with the help of dedicated observations collected over the Southern Great Plains, USA during the summer of 1997 by the ARM (Atmospheric Radiation Measurement) programme, in an SCM intensive observation period (IOP). Case 3 consists of a set of three periods of four or five days each, and includes several convective events.

As in Case 3, we use vertical profiles of temperature $T$, water-vapour mixing ratio $r_{\mathrm{v}}$ and horizontal wind, as well as the large-scale advection of temperature and moisture, provided every three hours by a constrained variational objective analysis of the available observations (hereafter referred to as the ARM analysis, see Zhang and Lin (1997) and Zhang et al. (2001) for details on the data and method). Accordingly, the CRMs use cyclic lateral boundary conditions. Similarly, time-varying surface heat fluxes are prescribed and horizontal mean winds are nudged towards the observed values with a nudging timescale of approximately two hours. Such a configuration ensures that the simulations are performed under realistic (even though idealized) environmental conditions. The CRMs and SCMs are initialized identically, with the same vertical profiles of temperature, moisture and wind. These profiles are applied homogeneously in the CRMs, except for a small amount of white noise applied to the temperature at the initial time step on the lowest model level.

Many convective events seen during the 1997 summer SCM ARM IOP were not directly linked to the local diurnal heating, though. Rather, these were mesoscale systems crossing, or partly advected into, the ARM domain, as discussed by Xie et al. (2002). A careful examination of the IOP led us to retain 27 June 1997, as this day was the least affected by the problem. Only weak rainfall rates were observed on this day with a maximum late in the afternoon (local time). Large-scale advection of temperature and moisture was weak. The diurnal-cycle case was then obtained by repeating this day. Note that this diurnal-cycle case is not designed for week-long simulations, as we did not attempt to modify the forcing dataset so as to get a strict balance of the moist static 

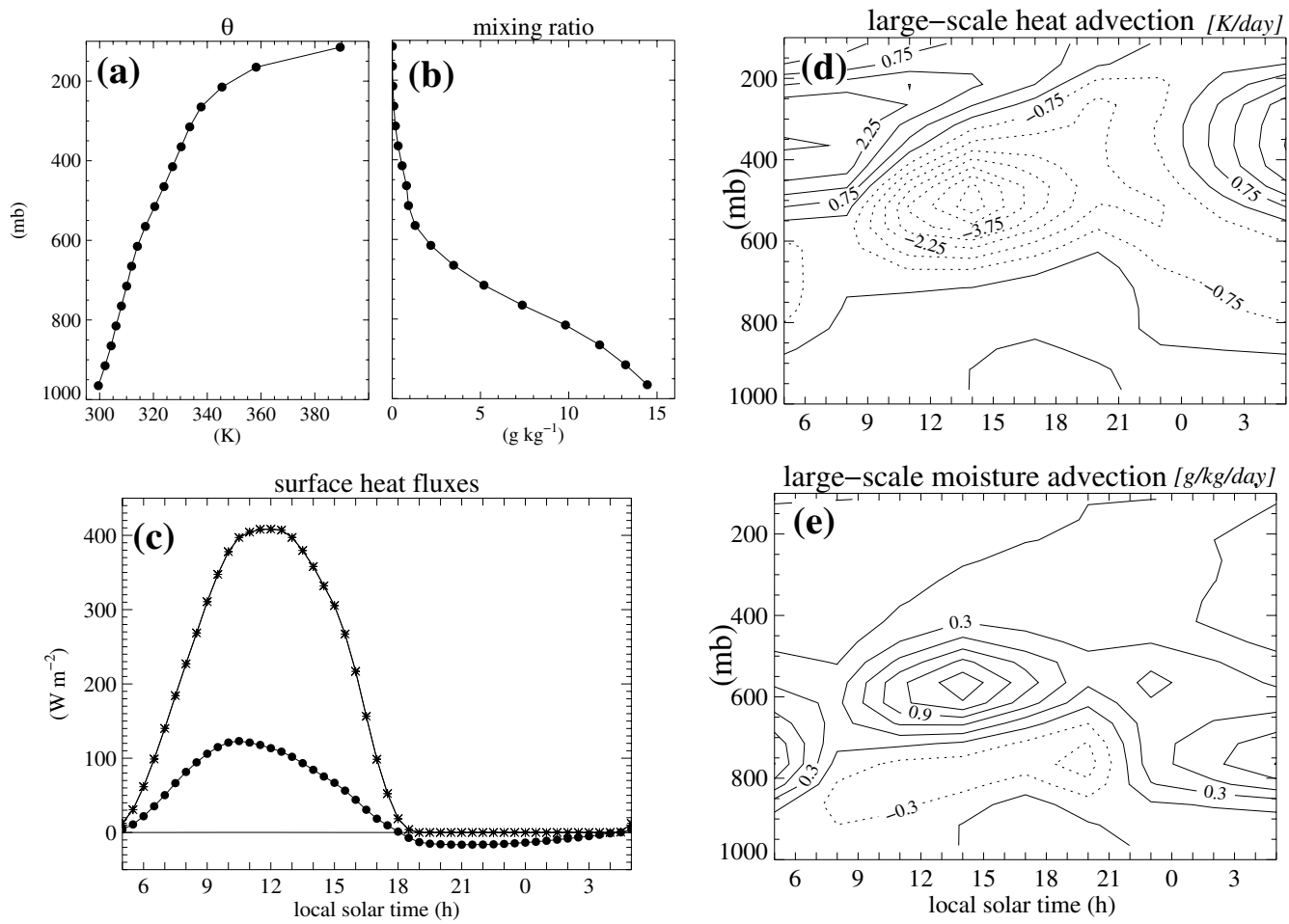

Figure 1. The simulation set-up: initial profiles of (a) potential temperature $\theta$ and (b) mixing ratio; (c) time-series of surface sensible-heat flux (black dots) and latent-heat flux (stars); time-height series of large-scale advection of (d) heat and (e) moisture.

energy budget. Indeed, observations do not show such a balance on a daily timescale. In contrast to the Case 3 set-up, for this diurnal-cycle case-study the start was shifted by 12 hours. Thus, simulations begin around sunrise (1130 UTC), instead of sunset (2330 UTC), as we are interested in the development of diurnal convection. Furthermore, one expects that the relatively coarse vertical resolution $(50 \mathrm{hPa})$ of the variational analysis is less of a problem at low levels before the development of the daytime convective boundary layer. The initial profiles of $T$ and $r_{\mathrm{v}}$ are shown in Figs. 1(a) and (b), respectively.

In addition, the surface heat fluxes provided by the variational analysis were modified in order to follow more closely the amplitude of their diurnal variation, as revealed by local measurements. As shown in Fig. 2, the measured surface heat fluxes always reach significantly larger maxima, and stay much closer to zero during nighttime than the ones provided by the variational analysis*. The Bowen ratio derived from the variational analysis was used to partition the total heat flux into sensible- and latentheat fluxes (Fig. 1(c)); its value decreases from $\sim 0.3$ early in the day to $\sim 0.2$ in the evening, i.e. the magnitude of the latent-heat flux is relatively large for this continental case. The total heat flux was then obtained from a slightly filtered composite $\dagger$ of three local datasets. The time sampling is 30 minutes instead of three hours for the product from the variational analysis. The difference obtained between the 24 -hour mean values

* This is the case for both versions V1 and V2 of the dataset.

$\dagger$ The aim of this filtering was to remove the local spikes occurring in association with the passage of clouds. 


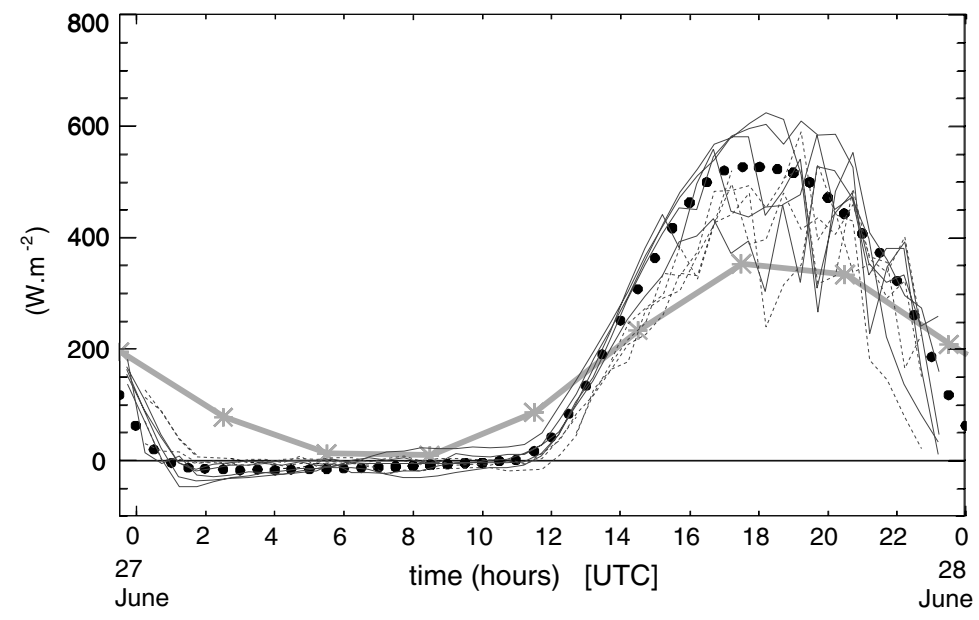

Figure 2. Time-series of the total surface heat flux $(H+$ LE) for 27 June 1997 from local measurements using either the Bowen ratio (thin solid lines) or the eddy correlation method (thin dotted line), from the variational analysis, i.e. the 'ARM dataset' (grey line), and used in the simulations (black dots). All the values correspond to 30-minute averages except for the grey line, which corresponds to three-hour sampling. See text for further details.

of the total heat flux retrieved by this method and those given by the variational analysis are less than $10 \%$, but the daily maxima of surface sensible- and latent-heat flux now reach $120 \mathrm{~W} \mathrm{~m}^{-2}$ and $\sim 400 \mathrm{~W} \mathrm{~m}^{-2}$ instead of $80 \mathrm{~W} \mathrm{~m}^{-2}$ and $270 \mathrm{~W} \mathrm{~m}^{-2}$, respectively. (Not surprisingly, these differences affect the dynamics of the simulated boundary-layer height and mean properties.) By our prescribing surface fluxes, any interactions between the clouds and the surface are switched off. In reality, clouds are expected to reduce the magnitude of the incoming solar flux at the surface, and therefore the heat fluxes (e.g. Machado et al. 2002). However, additional CRM experiments using a simple treatment of the cloud-surface flux interactions do not change the main conclusions of the present study.

Finally, in the results presented below, large-scale vertical advection provided by the variational analysis was also taken into account (Figs. 1(d) and (e)). Our conclusions are not very sensitive to this feature of the set-up though. The large-scale vertical motion was weak, with an absolute maximum of $\omega$ of around $0.075 \mathrm{~Pa} \mathrm{~s}^{-1}$ near $550 \mathrm{hPa}$, in the same range as Betts and Jakob (2002b). It led to local extrema of large-scale cooling and moistening of less than $6 \mathrm{~K} \mathrm{day}^{-1}$ and $2 \mathrm{~g} \mathrm{~kg}^{-1}$, respectively. The wind was relatively weak, compared with its values on the other days of the IOP, of the order of $5 \mathrm{~m} \mathrm{~s}^{-1}$ in the lower troposphere during daytime (not shown).

In comparison with the set-ups of previous deep convective cases for model intercomparisons (Redelsperger et al. 2000; Bechtold et al. 2000; Ghan et al. 2000; Xu et al. 2002; Xie et al. 2002), this idealized diurnal-cycle case is characterized by much weaker large-scale heat and moisture advection. Indeed, the maximum of the energy input to the system comes from the surface, around midday. In addition, as we are interested in relatively small timescales, we do not use the three-hour average time and time-height series as was done by $\mathrm{Xu}$ et al. (2002) and Xie et al. (2002), but rather the outputs provided at each time step by the SCMs and one-hour (or less) averaged fields from the CRMs. Finally, it is noticeable that this diurnal-cycle case is very similar to the fairweather cumulus case presented by Brown et al. (2002), based on one day of the same ARM SCM IOP (21 June 1997). The surface heat fluxes are very close; the large-scale 
TABLE 1. GENERAL INFORMATION ON THE MODELS

\begin{tabular}{|c|c|c|}
\hline Model acronym & Participants & References \\
\hline \multicolumn{3}{|c|}{ Single-column models } \\
\hline ARPEGE-Clim & Grenier & Gibelin and Dequé (2003) \\
\hline ARPEGE-NWP & Piriou & Piriou et al. (1999) \\
\hline ECMWF & $\begin{array}{l}\text { Chaboureau, Köhler } \\
\text { and Bechtold }\end{array}$ & Gregory et al. (2000) \\
\hline LMD & Tailleux & Le Treut and Li (1991) \\
\hline MetO & Petch & Pope et al. (2000) \\
\hline PLUMES & Cheinet & Cheinet $(2003,2004)$ \\
\hline HIRLAM-CLIM & Jones & Jones et al. (2004) \\
\hline \multicolumn{3}{|c|}{ Cloud-resolving models } \\
\hline $\mathrm{CRCP}$ & Grabowski & $\begin{array}{l}\text { Grabowski and } \\
\text { Smolardiewicz (1999) }\end{array}$ \\
\hline UKLEM & Petch & $\begin{array}{l}\text { Shutts and Gray (1994) } \\
\text { Swann (1998) }\end{array}$ \\
\hline MésoNH & Chaboureau and Tomasini & Lafore et al. (1998) \\
\hline
\end{tabular}

ARPEGE: Action de Recherche à Petite et Grande Échelle.

ARPEGE-Clim: The climate version of ARPEGE.

ARPEGE-NWP: The weather forecast version of ARPEGE.

ECMWF: European Centre for Medium-Range Weather Forecasts.

LMD: Laboratoire de Météorologie Dynamique.

MetO: Met Office global model.

HIRLAM-CLIM: HIgh-Resolution Limited Area Model.

CRCP: Cloud-Resolving Convective Parametrization.

MésoNH: Modèle Méso-échelle Non-Hydrostatique.

advection is similarly rather weak. A major difference between the two cases is the initial lapse rate; the stratification is more unstable in the present case, especially above $800 \mathrm{hPa}$.

\section{MOdELS}

Three CRMs, referred to as CRCP, MésoNH and UKLEM, and seven SCMs, referred to as ARPEGE-NWP, ARPEGE-Climat, ECMWF, HIRLAM-CLIM, LMD, MetO and PLUMES, participated in the study. They are listed in Table 1, along with the names of the participants and model references. Note that all the SCMs correspond to 1D versions of operational weather-forecast and/or climate 3D models, except PLUMES, which is a research 1D model. The main characteristics of these models are briefly summarized below.

\section{(a) CRMs}

The CRMs were used in their two-dimensional (2D) versions. During the course of the project, it appeared that the initiation of convection in the CRMs was sensitive to the treatment of small-scale processes (less than $\sim 1 \mathrm{~km}$ ). In particular, a $1 \mathrm{~km}$ resolution is still too coarse for a fully explicit simulation of convective boundary-layer circulations and shallow cumulus clouds appearing before the onset of precipitating convection. Therefore, these processes are partly handled by subgrid-scale parametrizations. Petch et al. (2002) showed that precipitating convection simulated by the UKLEM was delayed with a $2 \mathrm{~km}$ horizontal resolution, while a $250 \mathrm{~m}$ horizontal resolution led to satisfactory results. Therefore, the simulations of the UKLEM were performed with a $250 \mathrm{~m}$ horizontal resolution and, correspondingly, a high vertical resolution ranging from $47 \mathrm{~m}$ for the lowest layer to $165 \mathrm{~m}$ above $3 \mathrm{~km}$ (i.e. a stretched grid). A similar problem was encountered with the MésoNH CRM. There, when we kept the same $2 \mathrm{~km}$ 
horizontal resolution, the problem was greatly weakened by the introduction of subgridscale microphysical processes (namely condensation and autoconversion, following Redelsperger and Sommeria (1986)) along with modifications to the turbulence scheme, in particular the length-scale formulation following Bougeault and Lacarrère (1989). A similar $2 \mathrm{~km}$ resolution was adopted in CRCP. The vertical resolution for MésoNH and CRCP ranged from 75 to $700 \mathrm{~m}$ and from 102 to $530 \mathrm{~m}$, respectively. Simulations were performed on a $256 \mathrm{~km}(512 \mathrm{~km}$ ) wide domain with UKLEM (MésoNH and CRPCP), the domain height being $20 \mathrm{~km}$ or higher.

The turbulence scheme of CRCP differs from the two other CRMs. It is based on Troen and Mahrt (1986), whereas MésoNH and UKLEM use turbulent kinetic energy (TKE) based turbulence schemes. Liquid and ice microphysics are represented in the three CRMs, with either four (CRCP) or five (UKLEM and MésoNH) prognostic variables for cloud and precipitating hydrometeors mixing ratios. Radiative processes are also included. Finally, because of the sensitivity of the UKLEM to the noise applied to the initial temperature field (Petch 2004), two contrasted (in terms of rainfall rates) one-day UKLEM simulations are used below (plus one two-day run in Fig. 3).

\section{(b) SCMs}

All the SCMs are 1D versions of general-circulation models except for HIRLAMCLIM, a regional climate model, and PLUMES, a 1D research model. Deep convection is parametrized with mass-flux schemes (Arakawa and Schubert 1974) in all the SCMs. Most schemes include a treatment of convective downdraughts, except ARPEGE-Clim and PLUMES (Table 2). Similarly, most schemes use a convective available potential energy (CAPE) closure*. The closure of the operational ARPEGE-NWP is based on the moist static-energy convergence, but the model was also run with a CAPE closure. Convection triggering is generally based on conditional instability criteria; note, however, that more complex triggering functions are used in HIRLAM-CLIM, based on the work of Kain and Fritsch (1990). ECMWF is also using an entraining-parcel scheme in the boundary layer (Jakob and Siebesma 2003). Both schemes attempt to relate the triggering function more directly to the convective activity in the boundary layer. This feature is actually more common to convection schemes designed for mesoscale models (with horizontal grid size on the order of a few tens of kilometres), e.g. Bechtold et al. (2001). Note also the distinct design of PLUMES. This model was initially developed to represent dry and moist convective boundary layers through a unified approach involving a spectrum of entraining plumes. Its main characteristic is to provide a consistent treatment of the convective motions and the associated clouds. For this intercomparison study, a simple parametrization of precipitating processes has been introduced in the scheme, based on Bechtold et al. (2001), so that dry, shallow and deep convection are treated within a unified framework.

The distinction between shallow (non-precipitating) and deep (precipitating) convection varies among models. In short, in several models moist convection can be either shallow or deep. This involves different closure assumptions, entrainment rates, and links with the turbulence schemes. We refer to Lenderink et al. (2004) for information on the shallow convection and turbulence schemes; see also Jakob and Siebesma (2003) for a complete description of the decision tree implemented in the ECMWF model. (This tree decides for each model column whether convection will be activated or not and, if so, further chooses which type of convection is to be activated.)

\footnotetext{
${ }^{*}$ For mass-flux schemes, the closure refers to the hypothesis required to determine the convective mass flux at cloud base; this is not valid for PLUMES because of its design (unified scheme).
} 
TABLE 2. MAIN CHARACTERISTICS OF THE CONVECTION SCHEMES USED IN THE SINGLECOLUMN MODELS

\begin{tabular}{llccc}
\hline Model acronym & \multicolumn{1}{c}{ Reference } & Trigger & Closure & Downdraught \\
\hline ARPEGE-Clim & Bougeault (1985) & CI and MC & CAPE & No \\
ARPEGE-NWP & Bougeault (1985) & CI and MC & $h$ C/CAPE & Yes \\
ECMWF & Tiedtke (1989, 1993) & CI $^{+}$ & CAPE & Yes \\
& Gregory et al. $(2000)$ & & & \\
MetO & Gregory and Rowntree (1990) & CI & CAPE & Yes \\
PLUMES & Cheinet (2003, 2004) & CI & $\tau$ & No \\
LMD & Emanuel (1991) & CI & CAPE & Yes \\
HIRLAM-CLIM & Kain and Fritsch (1990) & CI and BL/E & CAPE & Yes \\
\hline
\end{tabular}

CI: Convective instability.

MC: Moisture convergence.

$h \mathrm{C}$ : Moist static energy convergence.

$\mathrm{CI}^{+}$: CI but based on an entraining parcel, as opposed to undilute.

$\tau$ : A characteristic lifetime of the spectrum of entraining plumes (note that the scheme closure is not based on the mass flux at cloud base as the scheme considers convective mass fluxes originating from the surface sublayer).

BL/E: Additional boundary-layer criteria, including a temperature perturbation function of the boundary-layer vertical velocity and assumed variance of the relative humidity at the lifting condensation level.

The parametrizations of clouds are quite different among the models too. Two of them have prognostic variables (ECMWF and MetO), e.g. cloud-water content and cloud fraction. Other SCMs use diagnostic relationships, e.g. based on mean relativehumidity criteria, and/or diagnosis of the subgrid variability of thermodynamical variables, or convective motions. The links with convective processes, as well as their strength, are quite diversely treated.

Most SCMs use their own radiative scheme, which allows interactions with the simulated cloud field. The time-height series of radiative heating rate provided with the model set-up was used only by PLUMES. However, sensitivity tests performed by some models with and without cloud-radiation interactions indicate that this mechanism is obviously not the dominant factor of the diurnal cycle of deep convection, at least for this case.

Simulations were performed with the vertical resolution of the operational version of the GCM/RCM from which the SCMs are derived. Thus, the number of vertical layers varies from 19 in LMD to 60 in ECMWF, the latter leading to a vertical resolution that is comparable to the one used in the CRMs. The time steps vary from $\sim 13$ to $30 \mathrm{~min}$. The results presented below correspond to the most up-to-date versions of the parametrizations. In effect, such a project systematically allows the raising of a number of specific problems, which go beyond the initial objectives of the study. For instance, the inspection of time-series of time-step values revealed high-frequency oscillations of the deep convection scheme, successively switched on and off in several models, which leads to non-physical noise in the time-series of rainfall, temperature and moisture, clouds and radiation fluxes. This problem is now weaker with updated versions of the parametrizations.

It is not the objective of this study to explain in detail the behaviour of each model. This is why, in the remainder of this paper, we distinguish between the results of the CRMs on the one hand, and the results of the SCMs on the other. The reader interested in the behaviour of any particular model is referred to the EUROCS web page*, where this information is available.

* http://www.cnrm.meteo.fr/gcss/EUROCS/Project.html 


\section{SCMs : surface rainfall}

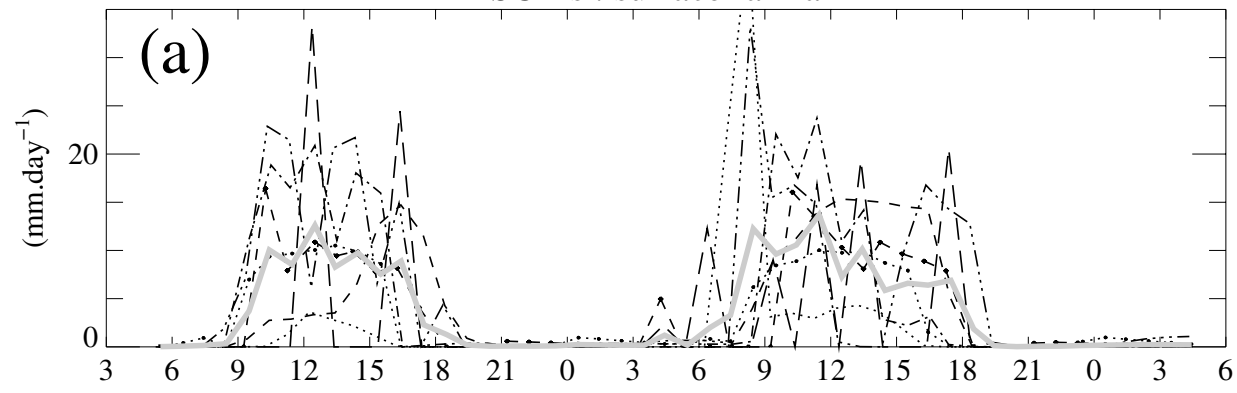

CRMs : surface rainfall

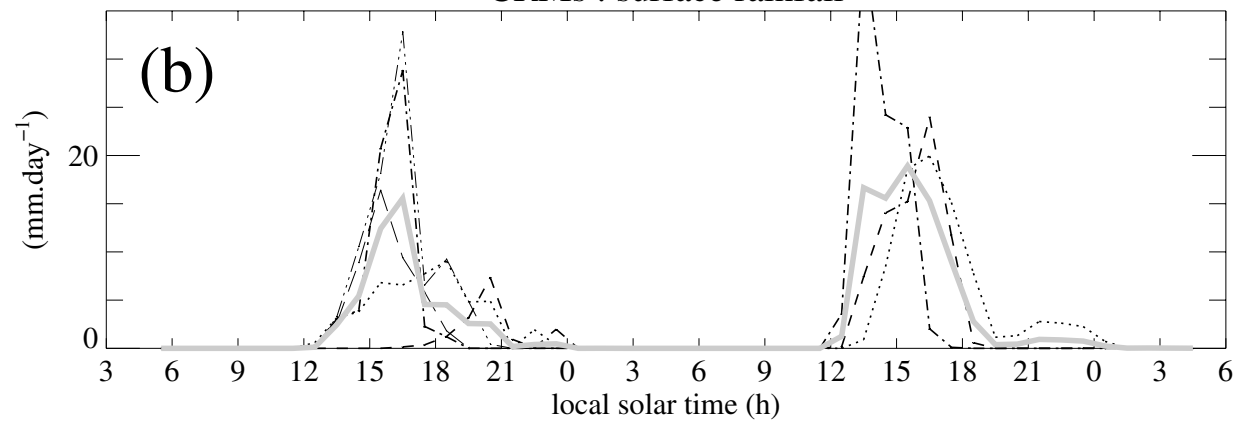

Figure 3. Time-series of the simulated surface rainfall over the two-day period from (a) the SCMs and (b) the CRMs. The thick grey curve corresponds to the average among models of each type. For the sake of clarity, different line styles are used for each model/simulation. Note, however, that in (b) the dashed line, the dotted line and the dashed dotted lines correspond to CRCP, MésoNH and UKLEM two-day simulations, and the two thinner lines correspond to the two 24-hour UKLEM runs.

\section{RESUlTs}

\section{(a) Precipitation}

Figure 3(a) shows the two-day time-series of rainfall obtained with the SCMs. A large scatter is found among the models. A feature shared by most SCMs, however, is the prediction of rainfall more or less in phase with the solar heating; it rains during daytime, from approximately three hours after sunrise to sunset, the rainfall rate being maximal often towards noon*. Two models show a distinct behaviour, HIRLAM-CLIM, and PLUMES, in predicting an onset of rainfall two to three hours later than the others do on the first day-note, however, the much lower amount of rainfall simulated by PLUMES (especially on the first day). Overall, it appears that, within this idealized framework, it is possible to reproduce the same weaknesses of convection schemes found for full 3D models.

The amount of rainfall varies among the CRM simulations (Fig. 3(b)). As discussed by Petch (2004), it can even vary substantially with a given CRM for slightly different initiation procedures. This finding was not analysed in detail by Xu et al. (2002), but their Fig. 4 reveals an even larger range of variation in CRMs for both the timing and amount of rainfall simulated when large-scale heat and moisture advection is weak.

\footnotetext{
* Precipitation is predominantly generated by the convection scheme in this case; the contribution from the stratiform scheme is negligible, when not zero, for all the SCMs.
} 
However, in contrast to the behaviour of most SCMs, it only rains after noon for all the CRMs (Fig. 3(b)), with a maximum in the afternoon/evening, which is consistent with the ARM analysis.

Deep convection, as measured by rainfall rates, is also frequently more active in the SCMs than in the CRMs (the two-day average surface precipitation ranges from 1.8 to $2.7 \mathrm{~mm} \mathrm{day}^{-1}$ in the CRMs, and from 2 to $5.6 \mathrm{~mm} \mathrm{day}^{-1}$ in the SCMs). This strong response of many SCMs to the daytime surface heating is also obvious in Xie et al.'s (2002) study, if one focuses in their Fig. 4 on the periods when observed large-scale advection and rainfall are weak-see also Zhang (2002). It suggests that the diurnal cycle of deep convection could be too large in some GCMs if the surface heat fluxes are not much weakened by the associated cloud cover. This is indeed the case over land in the tropics with the LMD GCM (Grandpeix, personal communication). Such a predominant regime of convective organization can efficiently prevent the generation of convection by other mechanisms.

Such a distinct behaviour found for the SCMs and CRMs allows us to address the following question: why does rainfall occur earlier in the SCMs than in the CRMs? We show below that this relatively well-shared behaviour of the SCMs occurs despite the fact that the SCM-simulated diurnal cycles of convection exhibit a variety of patterns.

In the following, we largely concentrate on the first day of simulation, as the second day of simulation is influenced by the first day's convective event in such a way as to complicate the multi-model analysis. This issue is further addressed by Petch (2004).

\section{(b) The diurnal cycle of convection in the CRMs}

As an illustration, Fig. 4 summarizes the results obtained with MésoNH CRM. From the early morning until $\sim 1300 \mathrm{~h}$ local solar time* the boundary-layer potential temperature $\theta_{\mathrm{BL}}$ increases by $5 \mathrm{~K}$ (Fig. 4(b)). At first, the boundary-layer specific humidity $q_{\mathrm{BL}}$ increases too, but begins to decrease earlier than $\theta_{\mathrm{BL}}$, due to mixing that efficiently redistributes moisture in the deepening convective layer. Accordingly, before noon, the lifting condensation level (LCL) increases, as it is predominantly controlled by the boundary-layer temperature $T_{\mathrm{BL}}$ variations at that time, while the level of free convection (LFC) decreases, more sharply, as it is more directly influenced by the boundary-layer equivalent potential temperature $\theta_{\mathrm{e}_{\mathrm{BL}}}$ (Figs. 4(a) and (b)). This is accompanied by a significant increase of CAPE, that reaches more than $2000 \mathrm{~J} \mathrm{~kg}^{-1}$ and a decrease of the convective inhibition (CIN) (Fig 4(c)) - note the identical time evolution of $\theta_{\mathrm{e}_{\mathrm{BL}}}$ and CAPE (Figs. 4(b) and (c)). By $1030 \mathrm{~h}$, the LFC and LCL have almost met each other, and the CIN has become negligible, $\sim 1 \mathrm{~J} \mathrm{~kg}^{-1}$ (Fig. 4(d)). This coincides with the appearance of the first clouds. From $1000 \mathrm{~h}$ until $1300 \mathrm{~h}$, these clouds do not deepen significantly and do not produce much rainfall either. This happens even though the CIN remains below $3 \mathrm{~J} \mathrm{~kg}^{-1}$ from $1000 \mathrm{~h}$ until $1300 \mathrm{~h}$, with a level of neutral buoyancy LNB around $250 \mathrm{hPa}$. Indeed, the two first rainfall peaks at $1300 \mathrm{~h}$ and $1500 \mathrm{~h}$ are weaker than the following ones, after $1600 \mathrm{~h}$. By that time, the deeper clouds have reached the LNB, whereas the LFC and CIN (CAPE) have already begun to increase (decrease). These tendencies persist until $2000 \mathrm{~h}$. The lower cloud-base heights have now reached higher levels. Indeed, the maximum cloud fraction has been shifted from low $(\sim 800 \mathrm{hPa})$ to high levels $(250 \mathrm{hPa})$ between $1200 \mathrm{~h}$ and $1600 \mathrm{~h}$ (not shown). The LCL also decreases, but not as sharply as it increased during the growing phase of the boundary layer, despite similar variations of $T_{\mathrm{BL}}(\sim 5 \mathrm{~K})$ due to lower values of $q_{\mathrm{BL}}$. A decrease of the LNB is obvious too; it also contributes to the sharp decrease of CAPE.

* In the rest of this paper, hours always refer to local solar time. 

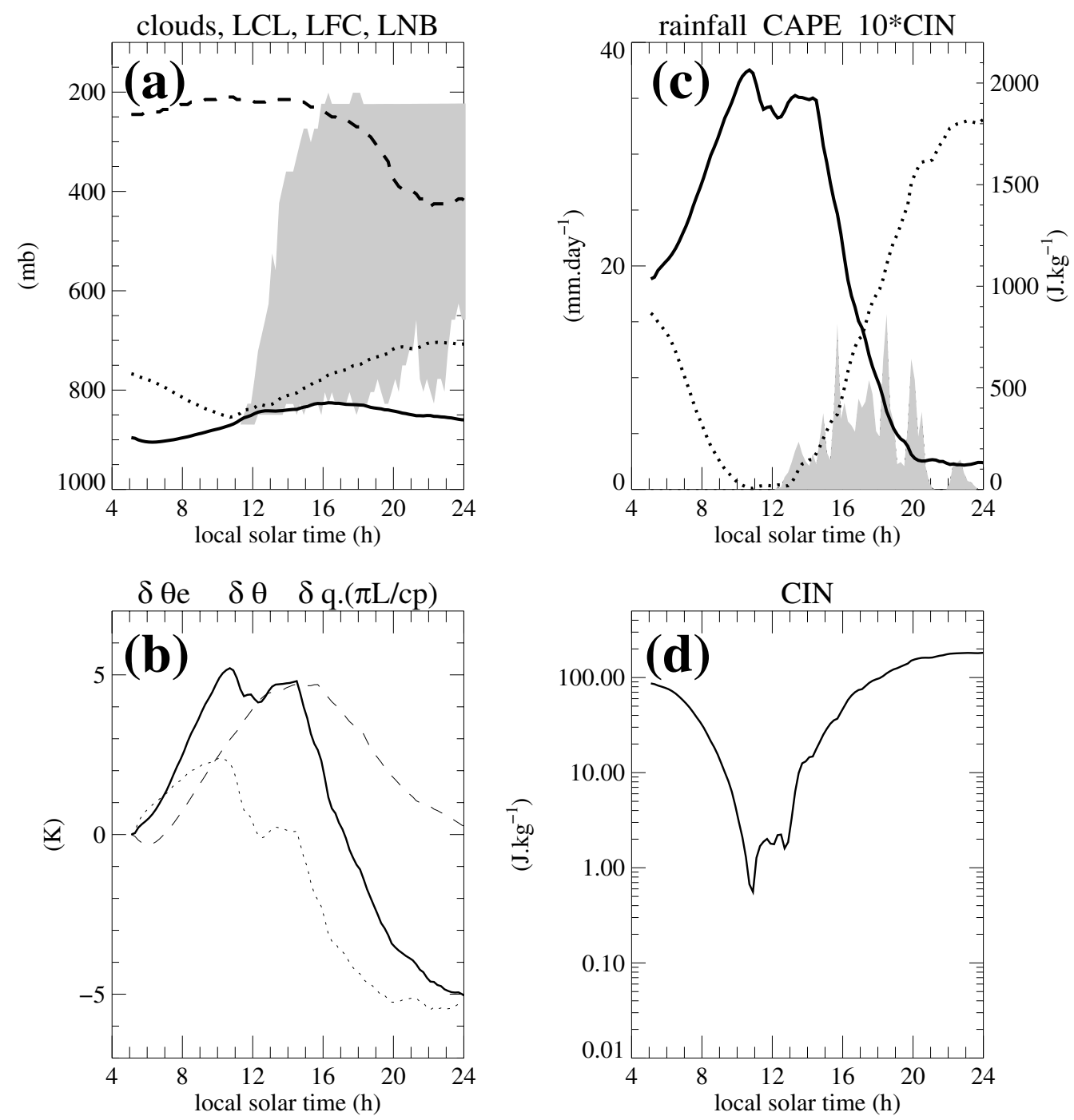

Figure 4. The MésoNH CRM results. (a) Time-series of the cloud field (the grey area delineates the minimum of cloud base and maximum of cloud-top height, diagnosed as the minimum (maximum) height where the horizontally averaged cloud fraction is greater than 1\%) showing the lifting condensation level (solid line), the level of free convection (dotted line) and the neutral buoyancy level. The calculations were performed for a parcel lifted from $100 \mathrm{~m}$ above ground level using the time-height series of 12-minute mean domain-averaged profiles. (b) The time-series of the departure from the initial value of the parcel, showing the changes in $\theta_{\mathrm{e}}$ (solid line), $\theta$ (dashed line) and $q\left(\Pi L / c_{p}\right)$ (dotted line). (c) The time-series of rainfall (shaded area), positive CAPE (solid line) and CIN (dotted line). (d) The time-series of CIN plotted on a logarithmic scale. $q$ is the specific humidity, $\Pi$ the Exner function, $L$ the latent heat of condensation and $c_{p}$ the heat capacity of air.

The reader is further referred to Chaboureau et al. (2004) for a more complete analysis of these CRM results.

Beyond their differences, all the CRMs provide a qualitatively similar picture. The main difference before noon is found for the boundary-layer moisture field, with CRCP (see discussion below). This simulation does not predict an increase of $q_{\mathrm{BL}}$ before $1100 \mathrm{~h}$, because of the faster growth of its boundary layer. A comparison of the two simulations of the UKLEM CRM also reveals the strong relationships between the 

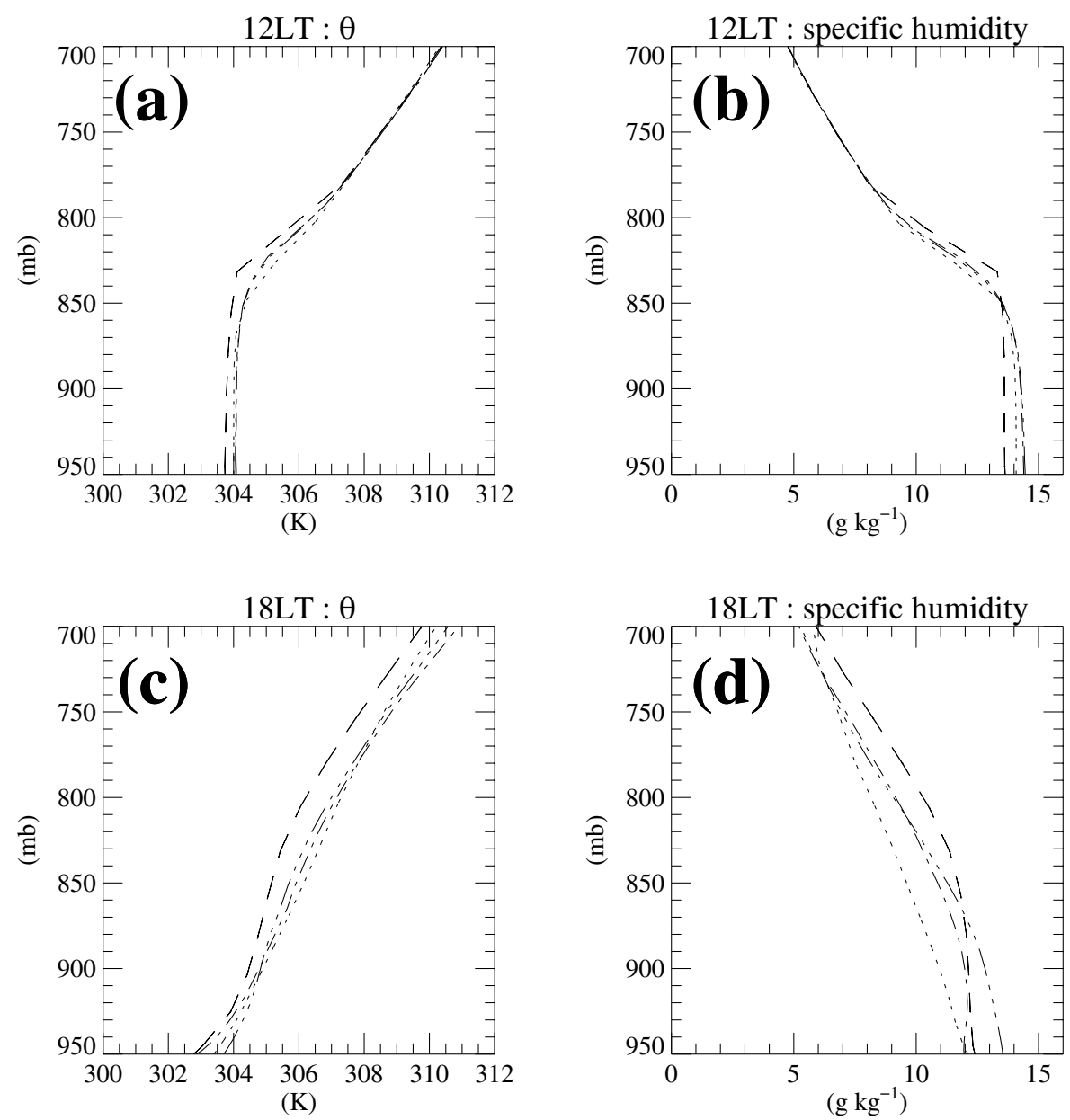

Figure 5. Vertical profiles of (a) the potential temperature and (b) the specific humidity at $1200 \mathrm{~h}$ (local solar time) for the CRMs (shown by different line types). (c) and (d) as (a) and (b), but at $1800 \mathrm{~h}$.

afternoon/evening time variations of $q_{\mathrm{BL}}, \mathrm{CAPE}, \mathrm{CIN}, \mathrm{LFC}, \mathrm{LNB}$ and rainfall. The simulation producing the more rainfall is characterized by the larger decrease (increase) of $q_{\mathrm{BL}}, \mathrm{CAPE}, \mathrm{LNB}$ (CIN, LFC).

\section{(c) Comparison of thermodynamic profiles in the CRMs and SCMS}

The CRM vertical profiles of potential temperature $\theta$ and specific humidity $q_{\mathrm{v}}$ at $1200 \mathrm{~h}$ are shown in Figs. 5(a) and (b). At that time, $\theta$ and $q_{\mathrm{v}}$ in the convective boundary layer agree reasonably well among the CRMs, with a boundary-layer height around $830 \mathrm{hPa}$. The convective boundary layer is slightly higher in CRCP (dashed line), and is accordingly drier. It is also slightly colder. The sharper better-defined boundarylayer top in CRCP (compared with UKLEM and MésoNH) most likely results from the differences in the turbulence schemes. Furthermore, they are consistent with the distinct behaviour of CRCP during the rest of the day, characterized by lower maxima of $\theta_{\mathrm{e}_{\mathrm{BL}}}$ and CAPE, higher minimum values of CIN and LFC, and an onset of rainfall shifted later in the afternoon/evening compared with the other CRM simulations. It is likely that the relatively smaller amount of rain predicted by CRCP (Fig. 3(b)) is connected to 

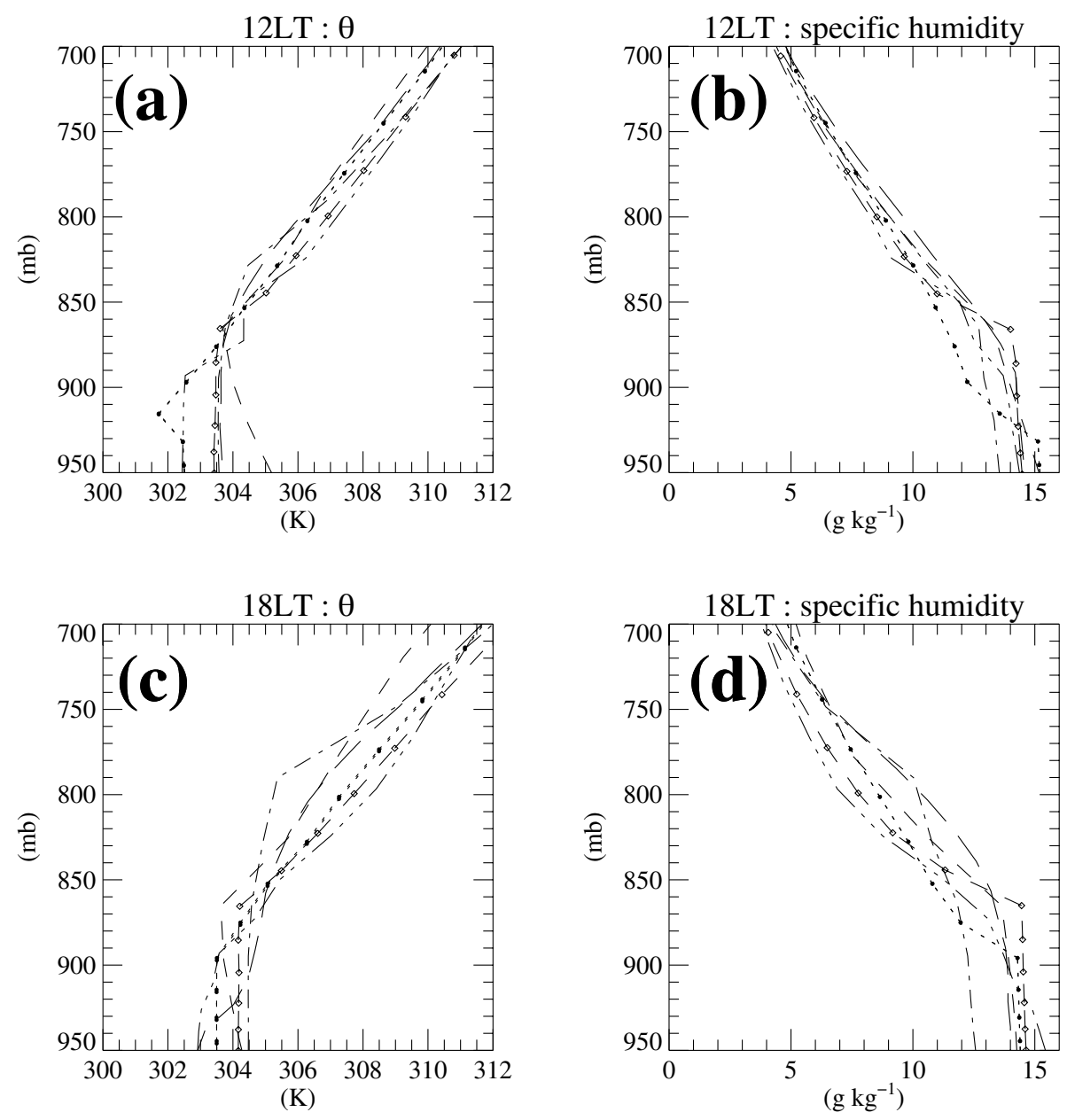

Figure 6. As Fig. 5, but for the SCMs (shown by different line types).

this late onset of deep convection. Indeed, the first surface rain occurs once the mean environmental conditions are already much less favourable to the development of deep convection than a few hours earlier, with a large CIN and weak CAPE (not shown).

At $1800 \mathrm{~h}$, the thermodynamic structure in the low levels has been dramatically modified (Figs. 5(c) and (d)). Apart from the differences in magnitude among them, all the CRMs predict an evolution of the well-mixed layer towards a stable cooler (by $\sim 1 \mathrm{~K}$ ) and drier (by $\sim 1-2 \mathrm{~g} \mathrm{~kg}^{-1}$ ) layer, indicative of the strong impact of convective downdraughts on the lower troposphere. The magnitude of the differences for such a precise time in the day is intimately linked to the particular sequence of convection occurring in each simulation. It is also probably related to the amplitude of the evaporation of raindrops at these heights. In addition, the choice of cyclic lateral boundary conditions as well as the two-dimensionality may affect the characteristics and impact of the CRM-simulated downdraughts. Overall, though, such a cooling and drying of the boundary layer induced by convective downdraughts is in agreement with a number of observational studies over land (e.g. Betts et al. 2002a,b). 


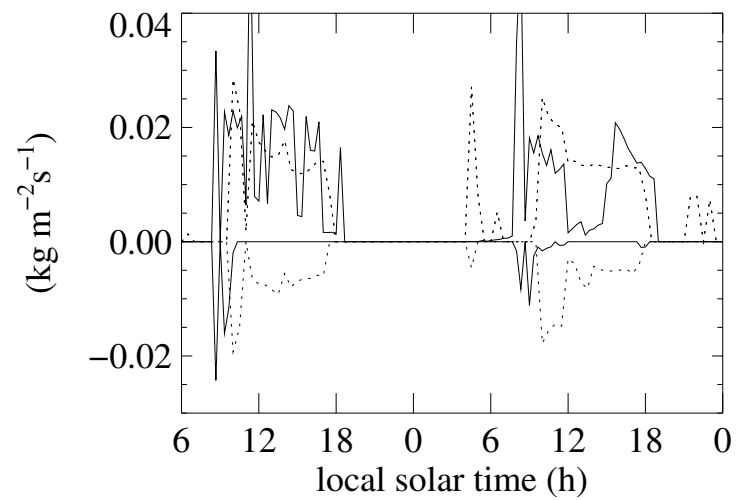

Figure 7. The two-day time-series of the vertically averaged convective upward and downward mass fluxes from two SCMs (full and dotted lines). The downward mass flux has been multiplied by 2 for clarity.

At $1200 \mathrm{~h}$, most SCMs nicely simulate a well-mixed layer, except for an unstable layer predicted by one of them* (Fig. 6(a)). However, a large scatter is already obvious. It concerns $\theta_{\mathrm{BL}}, q_{\mathrm{BL}}$ as well as the boundary-layer height. In the absence of deep convection, and with the same surface moisture fluxes, a shallower boundary layer is expected to yield a moister mixed layer than a deeper one, given the negative vertical gradient of $q_{\mathrm{v}}$ in the free atmosphere. This is partly consistent with the $q_{\mathrm{v}}$ profiles obtained in the boundary layer. For instance, the SCM predicting the higher mixed-layer height (dotted-dashed curve in Figs. 6(a) and (b)) is characterized by the driest boundary layer. These considerations do not explain the whole range of variations among SCMs, though. For instance, two models are colder than the others by $1 \mathrm{~K}$ in the boundary layer. For one of them, this is partly related to the effect of parametrized convective downdraughts that already altered the boundary-layer structure before noon. Indeed, a peculiar behaviour is found in some SCMs, with downdraughts whose intensity is higher in the morning with the first bursts of deep convection. This behaviour is quite persistent each morning, even when the mean conditions have changed. Later on, convective downdraughts usually become negligible or null. This is illustrated in Fig. 7 for the two SCMs (ECMWF and MetO) for which this feature is more pronounced $\dagger$. This view is not supported by the CRM results, indicating that, in the earlier stage of deep convection, the mass flux is predominantly upward, the downward convective motions developing later on from the mature to the decaying stage of precipitating convection (not shown). On the other hand, in one SCM the prediction of high cloud fractions at low levels in the morning led to the transient kink in $\theta$ found around $915 \mathrm{hPa}$. There is also a tendency for most SCMs to be moister than the CRMs in the boundary layer.

Above $780 \mathrm{hPa}$, the CRM profiles are very close to each other at $1200 \mathrm{~h}$ (Figs. 5(a) and (b)), and still close to the initial profile. In contrast, differences have already developed among the SCMs. They result from the early activation of the deep convection scheme in many SCMs, and from the scatter among the various parametrizations.

At $1800 \mathrm{~h}$, most SCM simulations still display a well-mixed boundary layer (Figs. 6 (c) and (d)), often warmer and moister than predicted by the CRMs. Thus, although deep convection occurred in the SCMs, it did not alter the lower levels in a similar way. Indeed, in the afternoon convective downdraughts, when parametrized, are quite weak

* This wrong behaviour is apparently linked to the implementation of the turbulence scheme in this SCM.

$\dagger$ This behaviour was pointed out by Betts and Jacob (2002a), but it is apparently shared by other schemes. 
when not null in the SCMs (except LMD), in agreement with Xie et al. (2002). This finding is consistent with the fact that most parametrizations have been designed with the help of well-documented oceanic tropical convective events (from GATE* and TOGACOARE $\dagger$ ). In such situations, the downdraught strength is typically weaker than over land (LeMone and Zipser 1980; Xu and Randall 2001). Furthermore, the evaporation in convective downdraughts is not simply linked to the convective downward mass flux, as opposed to condensation in convective saturated updraughts. It involves interactions with the microphysics; the rate of raindrop evaporation varies with the fall speed of the drops. These interactions are diversely treated in the SCMs, so that no simple conclusion can be drawn from downdraught convective mass fluxes alone. Additional simulations were performed with the convective downdraughts turned off for ARPEGE-NWP and ECMWF. They both indicated that convective downdraughts induce a cooling of the boundary layer, but do not affect much the low-level $q_{\mathrm{v}}$. A possible explanation for this behaviour is that the parametrized evaporation in the downdraughts is too large. A complete analysis of the impact of parametrized convective downdraughts obviously deserves a dedicated effort. The conclusion that can be drawn so far (for ECMWF and ARPEGE-NWP) is that the parametrized convective downdraughts do not significantly affect the lower-atmosphere temperature, and even less the moisture field, except for some detrimental cooling in the morning, which is too early. Note, however, that the parametrized convective downdraughts lead to larger relative humidity values in the boundary layer, accompanied by an increase in low-level clouds in both SCMs.

Finally, it must be noticed that HIRLAM-CLIM departs from the other models in this respect. This cannot be seen with instantaneous profiles, but the two isolated convective events predicted by this model are followed by strong drying and cooling of the low levels, caused by the intrusion of convective downdraughts in the boundary layer (not shown). The recovery of the boundary layer occurs within one to two hours, a behaviour that is consistent with local surface observations. As the parametrizations involved in this SCM have been designed for horizontal grid sizes of the order of $15 \mathrm{~km}$ (not $100 \mathrm{~km}$ or larger, as for the other SCMs), the comparison with local observations becomes meaningful. They indicate that this model behaves reasonably well in this respect, at least qualitatively.

The impact of daytime convection on the atmosphere is further quantified by the vertical profiles of $\theta_{\mathrm{e}}$ and the saturation deficit $\$$ at $2400 \mathrm{~h}$, once the convective activity is over for all the simulations (Fig. 8). The CRMs show an increase of $\theta_{\mathrm{e}}$ above $800 \mathrm{hPa}$. It reaches $\sim 5 \mathrm{~K}$ around $600 \mathrm{hPa}$, i.e. at the height where $\theta_{\mathrm{e}}$ was initially a minimum (Fig. 8(a)). Below $800 \mathrm{hPa}$, the modification varies more; three CRM-simulations predict a decrease of $\theta_{\mathrm{e}}$, the fourth a slight increase. This is also the simulation that predicts the weaker increase of the $\theta_{\mathrm{e}}$ minimum. A sharper vertical gradient of the saturation deficit accompanies the decrease of $\partial \theta_{\mathrm{e}} / \partial z$. At $2400 \mathrm{~h}$, the saturation deficit is larger below $800 \mathrm{hPa}$ and smaller above, with magnitudes on the order of a few $\mathrm{g} \mathrm{kg}^{-1}$ (Fig. 8(b)). Note that the CRM-simulated evolution of the profiles of $\theta_{\mathrm{e}}$ and the saturation deficit exhibit vertical signatures similar to the ones provided by the ARM analysis, even though we did not follow this dataset exactly in the set-up of the present case (Fig. 9).

The SCMs also predict some increase of $\theta_{\mathrm{e}}$ by a few $\mathrm{K}$ in the free troposphere, but often of smaller magnitude, despite the higher (on average) rainfall rates (Fig. 8(c)).

\footnotetext{
* GARP (Global Atmospheric Research Programme) Atlantic Tropical Experiment.

$\dagger$ Tropical Ocean Global Atmosphere - Coupled Ocean Atmosphere Response Experiment.

$\ddagger$ Defined as the difference between the saturation value of $q_{\mathrm{v}}$ and its actual value.
} 

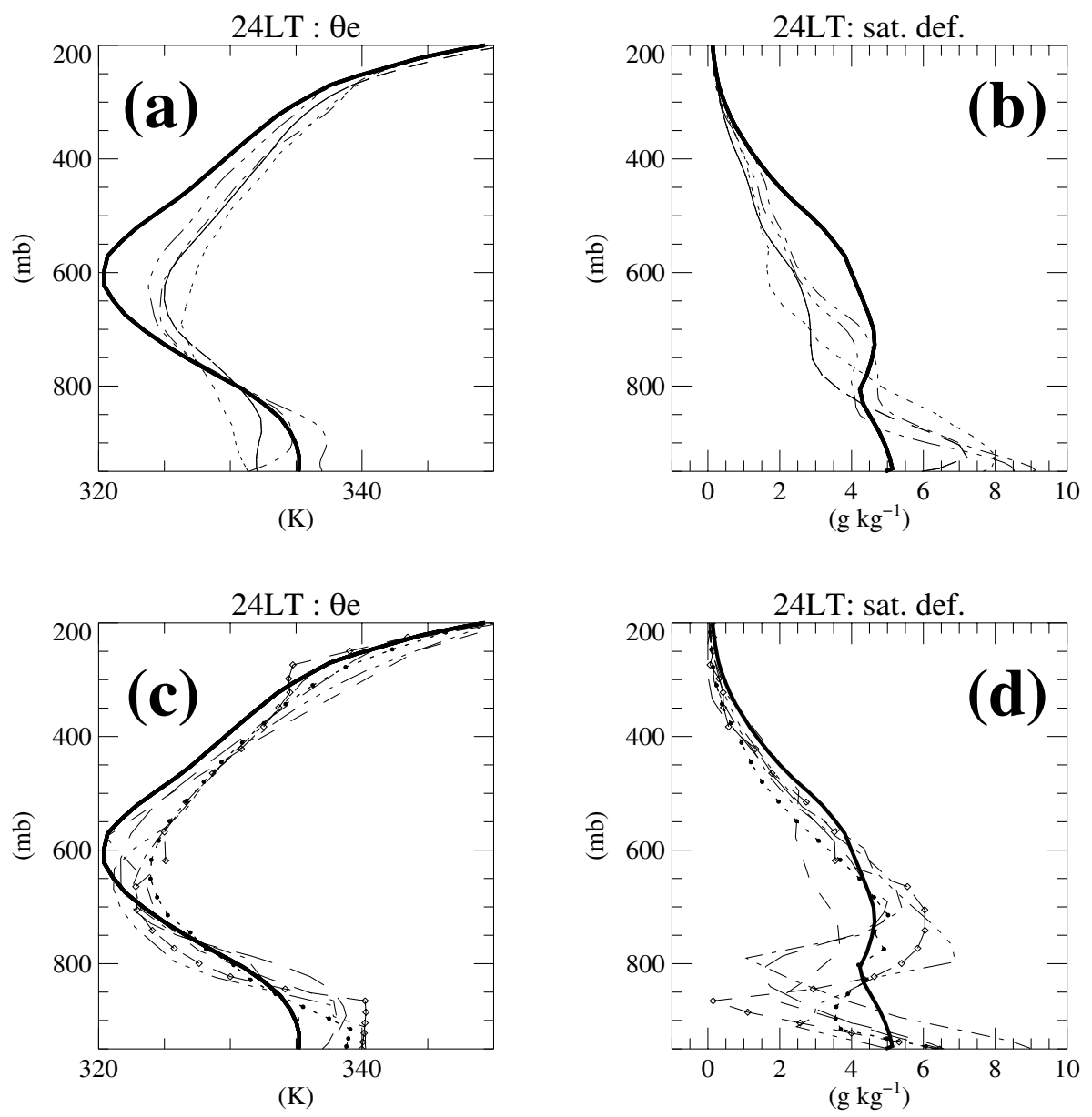

Figure 8. Vertical profiles of (a) the equivalent potential temperature $\theta_{\mathrm{e}}$ and (b) the saturation deficit at midnight (i.e. after 19 hours of simulation) for the CRMs; (c) and (d) as (a) and (b), but for the SCMs. The thick solid lines correspond to the initial profiles.
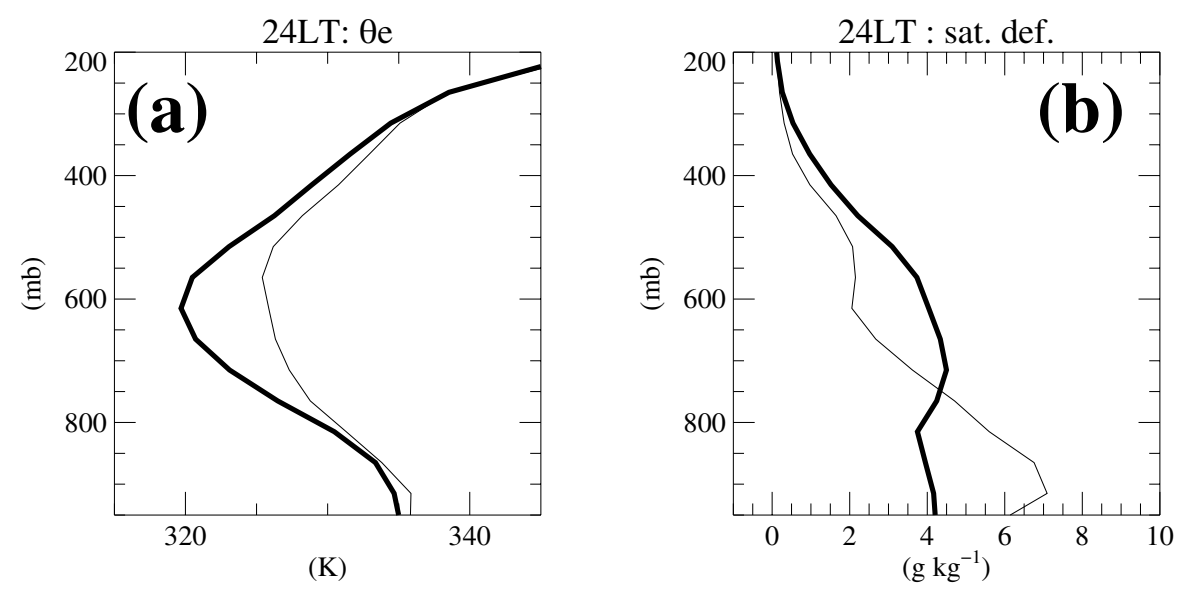

Figure 9. As Fig. 8, but for the ARM dataset. 
A variation in the height of the minimum of $\theta_{\mathrm{e}}$ is also obvious in several SCMs. Below $850 \mathrm{hPa}$, all SCMs predict an increase of $\theta_{\mathrm{e}}$ (Fig. 8(c)), as opposed to the decrease of $\theta_{\mathrm{e}}$ occurring in most CRM simulations. This feature is largely explained by the low levels being usually moister in the SCMs than in the CRMs. The vertical profiles of saturation deficit (Fig. 8(d)) show a variety of structures. Common to several models is a sharp minimum of the saturation deficit, located typically between 840 and $880 \mathrm{hPa}$, reminiscent of the daytime mixed layer. This structure was present in all CRMs at noon too (see Chaboureau et al. 2004), but it was progressively eroded by the deepening convective activity so that it had totally disappeared at $2400 \mathrm{~h}$. Accordingly, above $800 \mathrm{hPa}$, the saturation deficit in most SCMs is larger at the end of the day than it was at sunrise. This further favours the maintenance of low-level clouds that persist throughout the night in several SCMs.

\section{(d) The apparent heat source $Q_{1}$, the apparent moisture sink $Q_{2}$, and $Q_{1}-Q_{2}$}

In large-scale models, the apparent heat source $Q_{1}$ and moisture sink $Q_{2}$ are commonly used to quantify the subgrid-scale processes involved in temperature and moisture budgets. This includes the contribution of turbulence, moist convection, resolved microphysics, and radiative parametrizations, i.e. all of the processes but large-scale advection. The vertical structures of $Q_{1}$ and $Q_{2}$ are consistent among the CRMs (Figs. 10(a) and (c)). The maximum heating is located towards $500 \mathrm{hPa}$. This vertical structure is fairly similar in the SCMs (Fig. 10(b)). The magnitude of the negative peak towards $300-250 \mathrm{hPa}$ is linked to the radiative cooling occurring at the top of the clouds, and depends on the characteristics of the parametrized clouds. Indeed, some SCMs do not exhibit such a negative minimum, as they remain cloud free (see next paragraph). Consistent with the time variations of the saturation deficit, the convection is responsible for a drying of the lower levels and a moistening of the free troposphere, the magnitudes of $Q_{2}$ being at least as large as those of $Q_{1}$ (of the order of several K day ${ }^{-1}$, Fig. 10(c)). The ARM analysis also indicates such a vertical structure of $Q_{2}$ (not shown).

This structure is very different in the SCMs (Fig. 10(d)). In particular, $Q_{2}$ is frequently negative below $850 \mathrm{hPa}$, and much weaker than in the CRMs above $600 \mathrm{hPa}$. This finding suggests that convective transport of moisture by the deep convection schemes is too low in the SCMs. Between these heights, some models predict a drying that largely explains the lowering of the $\theta_{\mathrm{e}}$ minimum seen in Fig. 8(c).

$Q_{1}-Q_{2}$ is indicative of the convective transport of $\theta_{\mathrm{e}}$, if one neglects the ice-phase processes and radiation. Its vertical structure shows that daytime convective processes led to a stabilization of the atmosphere in CRMs, with positive values of $Q_{1}-Q_{2}$ above $800 \mathrm{hPa}$, and negative or weaker values below (Fig. 10(e)). The vertical profiles of $Q_{1}-Q_{2}$ are often more complex in the SCMs, with significant scatter among them (Fig. 10(f)) because of the variety of assumptions involved in the parametrization of convective fluxes. The layer of high $Q_{1}-Q_{2}$, between 600 and $400 \mathrm{hPa}$ is close in magnitude to the one in the CRMs but, in contrast to the CRMs for which both $Q_{1}$ and $-Q_{2}$ contribute to this maximum, it is mostly due to the $Q_{1}$ peak in the SCMs. This indicates that any further investigation of this issue requires a careful examination of the subgrid-scale fluxes parametrized by the turbulence, the shallow and deep convection schemes. Overall, this behaviour of the SCMs (adjusting towards more unstable conditions than the CRMs) is consistent with the results of Bechtold et al. (2000) and the discussion of Swann (2001), who argued that bulk mass-flux convection schemes might lead to a 'modelled convective atmosphere being artificially unstable in order to maintain deep convection'. 

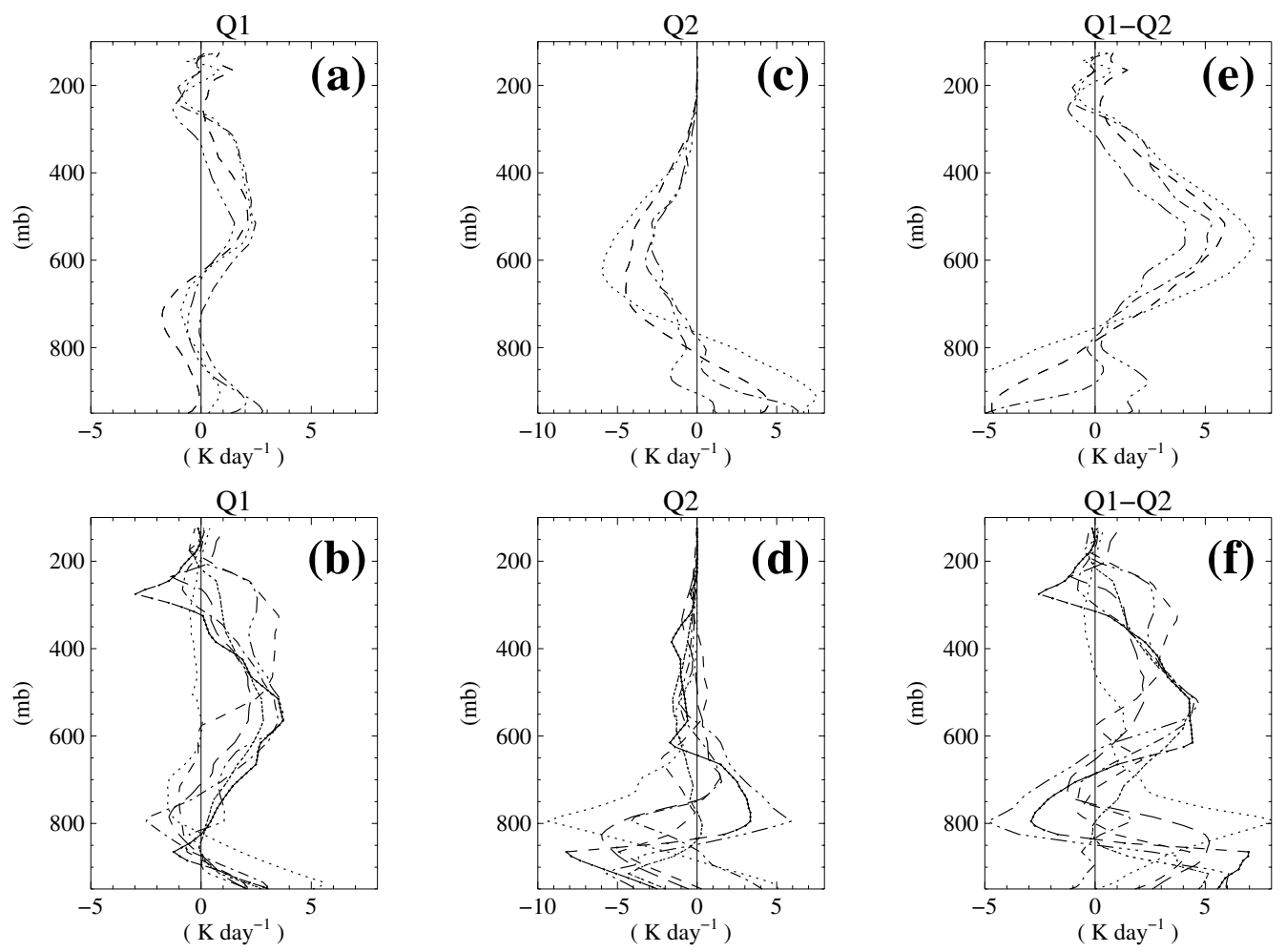

Figure 10. Vertical profiles of apparent heat source $Q_{1}$ for (a) the CRMs and (b) the SCMs; (c) and (d) as (a) and (b), but for the apparent moisture sink $Q_{2}$; and (e) and (f) as (a) and (b), but for $Q_{1}-Q_{2}$ (18-hour average, between $0600 \mathrm{~h}$ and midnight).

Considering now the daytime evolution of $Q_{1}$ and $Q_{2}$, the minimum of $Q_{2}$ (i.e. the maximum convective moistening) averaged over the layer $(800 \mathrm{hPa}, 100 \mathrm{hPa})$ is systematically earlier than the maximum of $Q_{1}$ by a few hours (Fig. 11). This feature is consistent with a progressive growth of deep convection. The first convective cells essentially moisten the atmosphere rather than directly producing surface rainfall. This phase shift of $Q_{1}$ and $Q_{2}$ is lacking in most SCMs (Fig. 12). Furthermore, they predict instead a coupled heating/drying of the free troposphere. Note that the ARM analysis also indicates negative values of $Q_{2}$ (i.e. moistening) for these heights.

\section{(e) Clouds}

The occurrence of moist deep convection involves the development of clouds. Previous intercomparison studies (Redelsperger et al. (2000), and Xu et al. (2002) for CRMs, and Bechtold et al. (2000), Ghan et al. (2000), and Xie et al. (2002) for SCMs) have already documented this point. The cases considered by these studies were, however, largely forced by large-scale cooling and moistening, which typically reached several tens of $\mathrm{K} \mathrm{day}^{-1}$ and more than $10 \mathrm{~g} \mathrm{~kg}^{-1} \mathrm{day}^{-1}$, respectively. Here, this is not the case. This different configuration highlights additional features of parametrized convective clouds, as presented below.

Figure 13 shows time-series of cloud-top height. In the CRMs, the first clouds appear between $1000 \mathrm{~h}$ and $1100 \mathrm{~h}$. These are initially forced clouds, i.e. with cloud tops below the LFC. This is not the case anymore after noon, but it still takes a few hours 

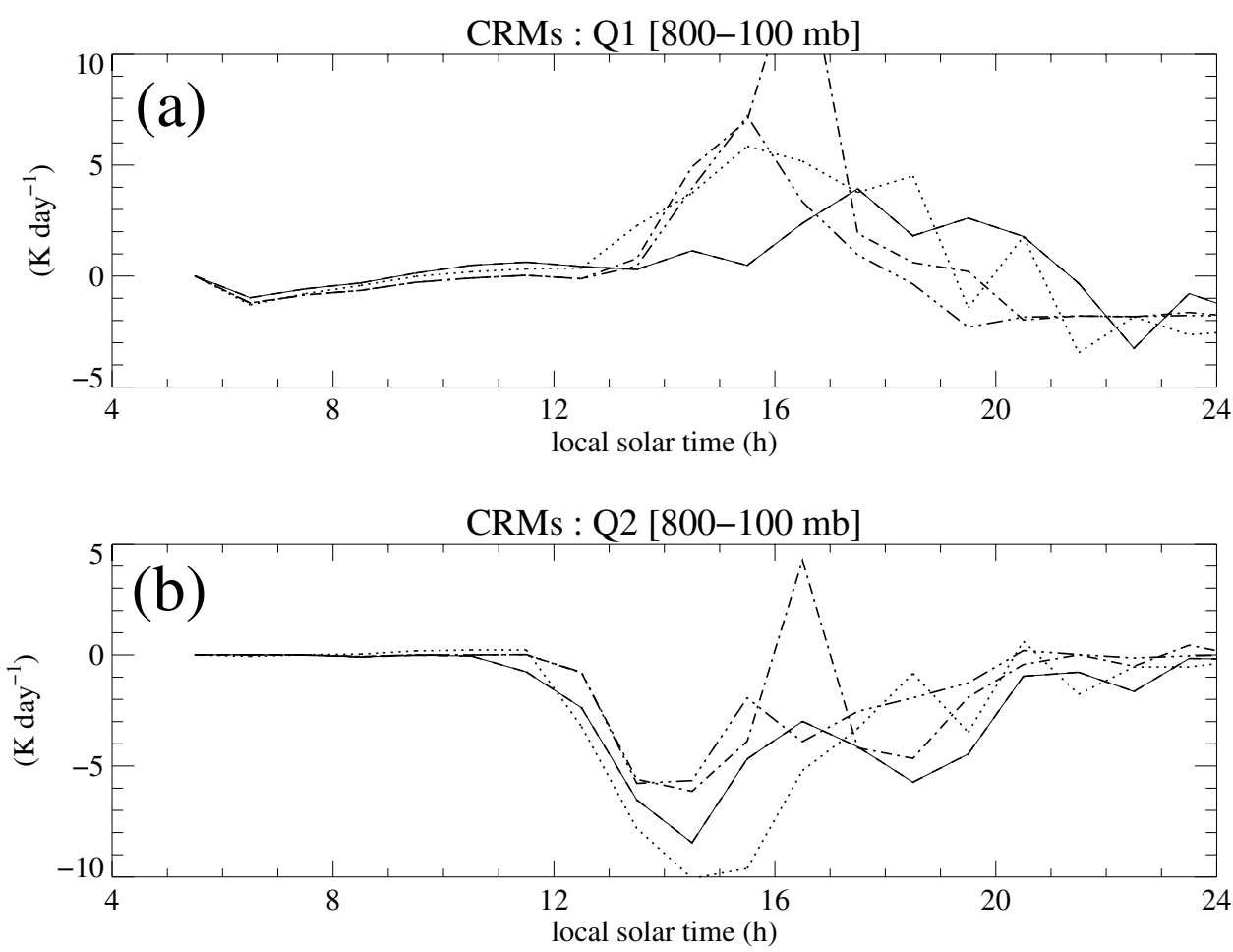

Figure 11. Time-series of the one-hour means forecast by the CRMs of (a) $Q_{1}$ and (b) $Q_{2}$ averaged over the layer $800-100 \mathrm{hPa}$.

before these clouds reach their maximum level, towards $250 \mathrm{hPa}$, i.e. close to the LNB. There is a good agreement between UKLEM and MésoNH, even though their resolution and subgrid-scale parametrizations are different, while the first clouds appear more than an hour later in CRCP, and their vertical growth is slower. However, in the three CRMs, the appearance of the first clouds precedes the surface rain by several hours. On the basis of these simulations only, we cannot definitively assess the sensitivity of this result to CRM resolutions and subgrid-scale parametrizations. However, this behaviour is in general agreement with several observational studies, which indicate that the build-up of diurnal deep convection typically takes a few hours (e.g. Bergman and Salby 1997; Wylie and Woolf 2002).

The most striking characteristic of cloud-top heights predicted by the SCMs (Fig. 13(b)) is that, for most of them, they reach their highest level quasi-instantaneously, within a time step. Thus, at $0900 \mathrm{~h}$, the cloud-top height is already above $300 \mathrm{hPa}$ in three models. The same applies to HIRLAM-CLIM except that clouds appear at noon. ARPEGE-Clim produces only low clouds, activated by a statistical cloud scheme, and LMD does not diagnose any cloud. This simply reflects the lack of interactions between the convection and cloud schemes. These SCMs are producing what might be considered as 'clear sky convective rainfall'. Finally, note the distinct progressive growth in PLUMES (Fig. 13(b), dotted line), which shares the same characteristic as the CRMs. All the other SCMs, characterized by different schemes/assumptions for shallow or deep convection, do not handle this phase properly. 

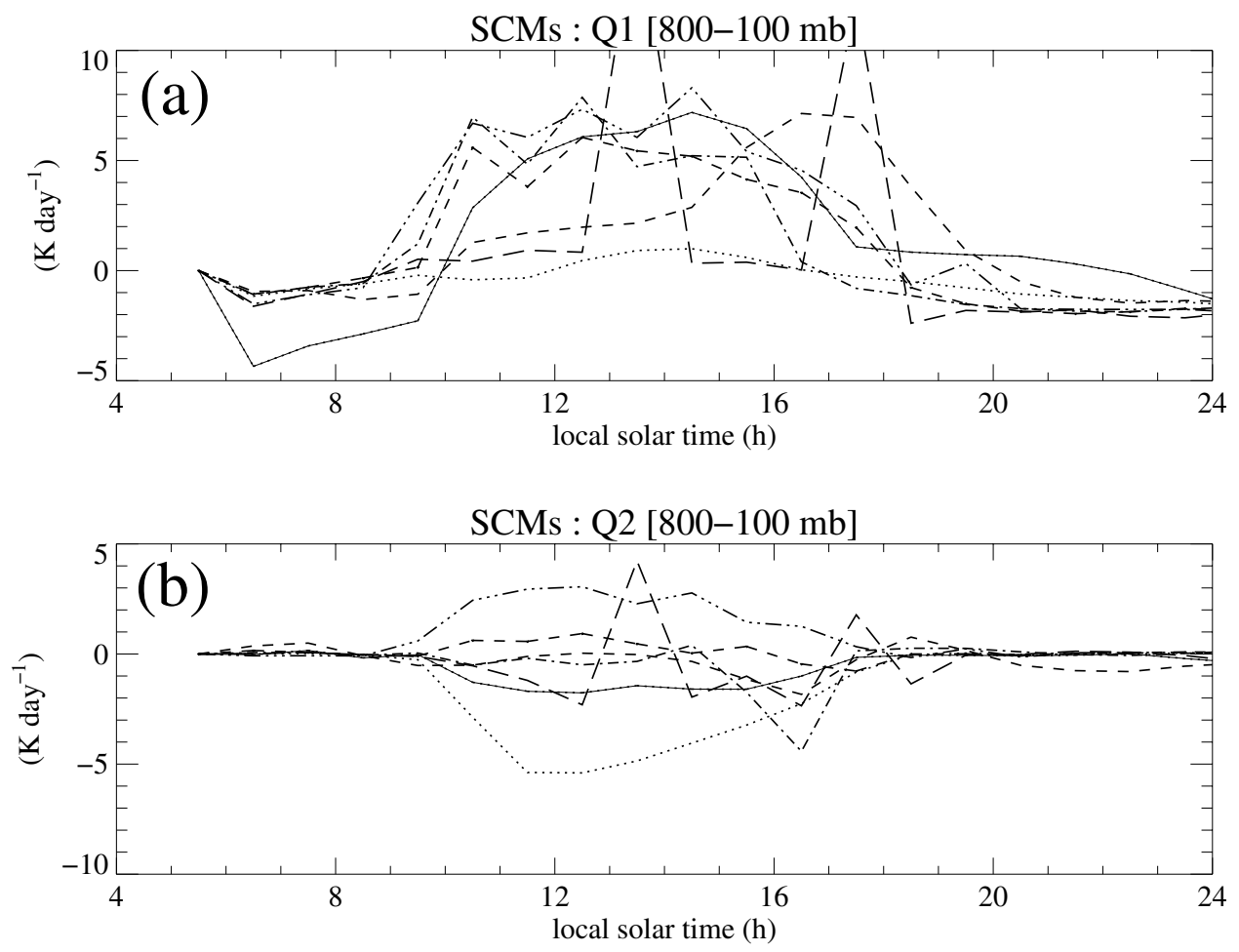

Figure 12. As Fig. 11, but for the SCMs.

In the present case, the slow build-up of deep convection appears as an efficient mechanism for delaying the onset of convection in the CRMs. In contrast, the instantaneous production of thick precipitating clouds in association with the convection scheme contributes to the advance of rainfall in the SCMs. This slow growth seems to be partly related to the sensitivity of convection to the moisture fields in the CRMs, as stressed by Redelsperger et al. (2002), and further investigated by Chaboureau et al. (2004). Such sensitivity is apparently lacking in many SCMs. This point is directly addressed by Derbyshire et al. (2004). They show that CRMs predict two different regimes of convection in response to modifications of the moisture field. Under dry conditions, relatively shallow ( $\sim$ cumulus congestus) precipitating clouds are dominant, whereas deep convective clouds are found under moist conditions. The present analysis is consistent with their findings.

Considering now the mean properties of the simulated clouds, as characterized by the cloud fraction and in-cloud water (Fig. 14), we find a broad agreement with previous intercomparison studies. Caution is required when comparing cloud fractions obtained from CRM and SCM simulations. In effect, the cloud fraction is predicted in the SCMs, but simply diagnosed in the CRMs from the hydrometeor fields following the criteria defined by $\mathrm{Xu}$ and Krueger (1991). In the CRMs, the cloud fraction increases with height, from a few percent below $500 \mathrm{hPa}$ to 5-15\% around $250 \mathrm{hPa}$ (Fig. 14(a)). These two maxima occur successively, not at the same time. The range of variations appears to be linked to both parametrization of microphysics and convective activity; the simulations predicting less rain also produce less high-cloud cover. The in-cloud water values agree reasonably well among the CRMs (Fig. 14(c)). There is apparently 

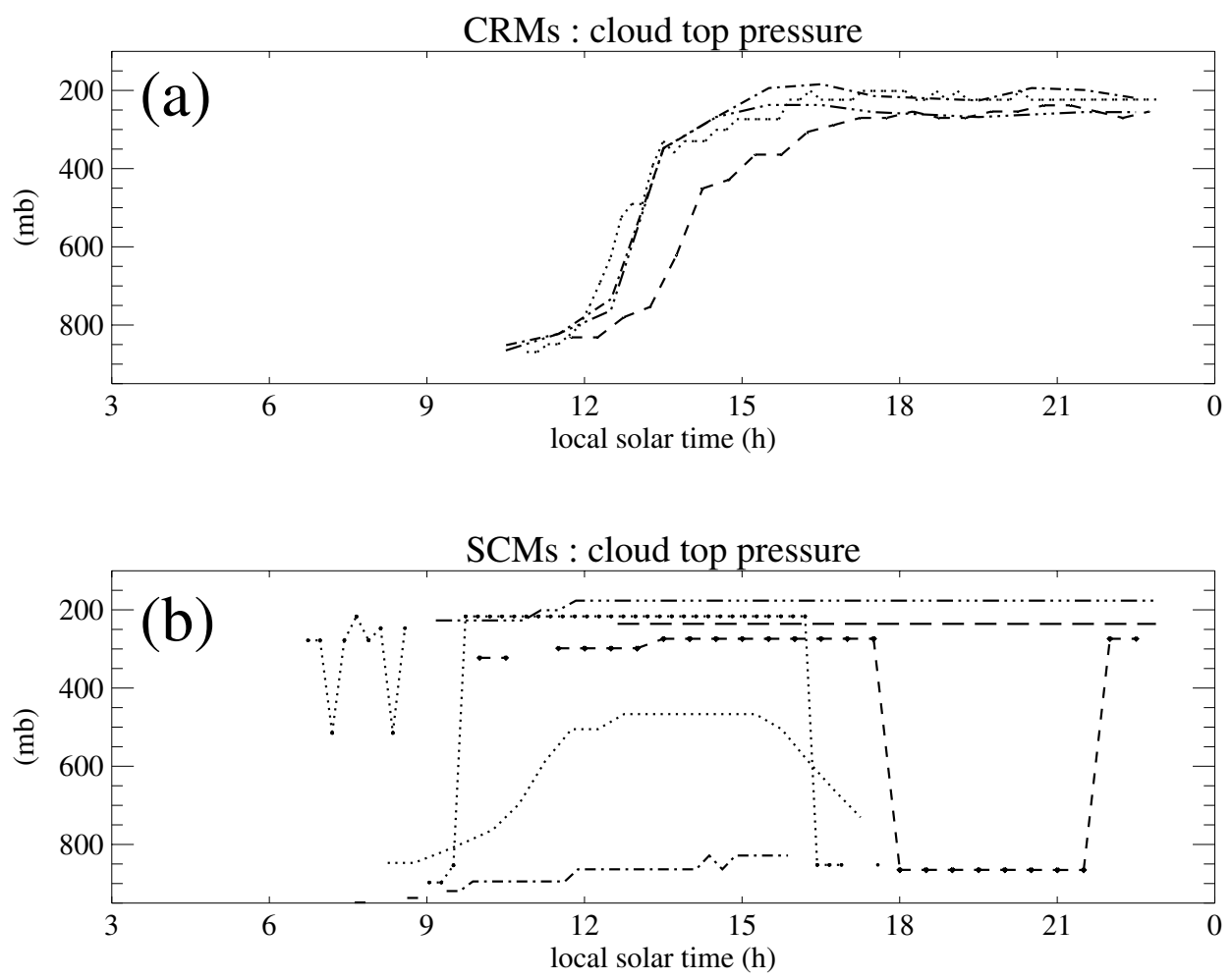

Figure 13. Time-series of maximum cloud-top pressure for (a) the CRMs and (b) the SCMs.

a tendency for low-resolution simulations to predict more liquid cloud water in the early stage of moist convection than is obtained with the high-resolution simulations of UKLEM. This is still obvious on these time-mean profiles. Several SCMs similarly exhibit two maxima (but they do not result from the same time evolution). Cloud fractions tend to be larger, but still less than $25 \%$ maximum. Large low-level cloud fractions are found; they correspond to clouds remaining throughout daytime and frequently night-time, in association with large values of relative humidity at these heights. Consistent with Lenderink et al. (2004), the in-cloud water can be quite large in the SCMs. In the present case, wrong prediction of low-level clouds (rather than high clouds) appears as a zero-order problem in terms of the surface heat budget. In a framework allowing interactions with the surface, it is clear that these large cloud fractions and amounts would have significantly affected the surface heat fluxes. Conversely, the lack of clouds would have induced systematic biases.

\section{(f) Diurnal cycle of atmospheric stability}

The diurnal cycle of convection over land is linked to the destabilization of the lower levels by daytime surface heating, which produces a clear signal in the stratification of the atmosphere. This motivated the stability analysis presented below. Figure 15 shows a scatter plot of $\theta_{\mathrm{e}}$ in the boundary layer $\left(\theta_{\mathrm{e}_{\mathrm{BL}}}\right)$ versus CAPE. On such a timescale (one day), these two parameters are particularly well correlated in CRMs-such a relationship is also given by observations; e.g. Machado et al. (2002). Before noon, $\theta_{\mathrm{e}_{\mathrm{BL}}}$ increases by approximately $5 \mathrm{~K}$, while CAPE grows from $\sim 1000 \mathrm{~J} \mathrm{~kg}^{-1}$ to more 

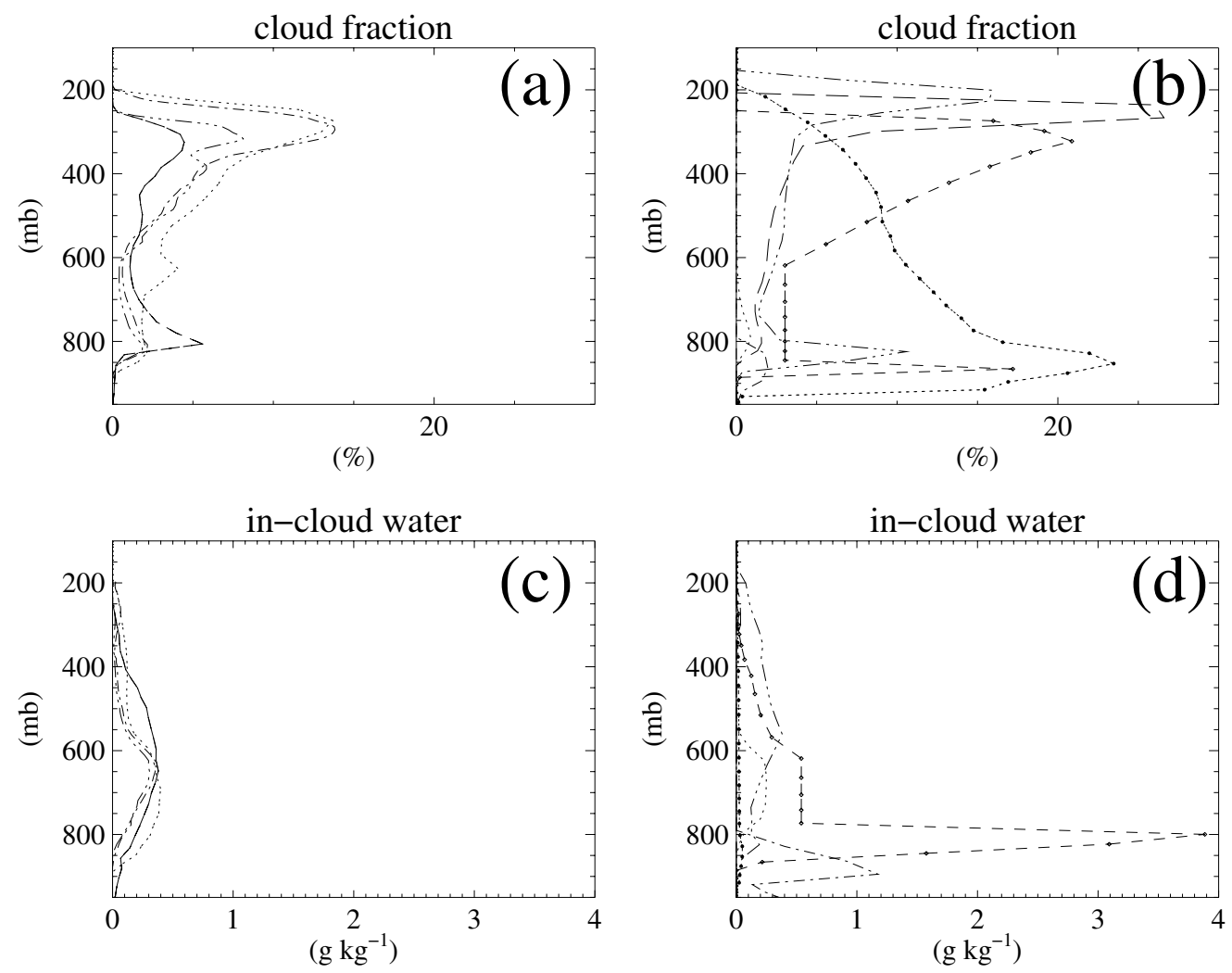

Figure 14. Vertical profiles of the cloud fraction (a) from the CRMs and (b) the SCMs, (c) and (d) as (a) and (b), but for the 'in-cloud' cloud water, corresponding to the time-average of the 'in-cloud' cloud water computed for each time step (for the SCMs) and time sample (for the CRMs) as the cloud water divided by the cloud fraction (time average between $0600 \mathrm{~h}$ and midnight).

than $2000 \mathrm{~J} \mathrm{~kg}^{-1}$. Their fluctuations are then weaker until $1500 \mathrm{~h}$, and then both $\theta_{\mathrm{e}_{\mathrm{BL}}}$ and CAPE decrease sharply. For a given $\theta_{\mathrm{e}_{\mathrm{BL}}}$ value, the corresponding CAPE is lower during the afternoon/evening (when $\theta_{\mathrm{e}_{\mathrm{BL}}}$ decreases) than during the morning (when $\theta_{\mathrm{e}_{\mathrm{BL}}}$ increases), as a result of convective activity. The differences are of the order of a few tens to a few hundreds of $\mathrm{J} \mathrm{kg}^{-1}$. They vary among the CRM simulations. For a given model, they can be directly linked to the intensity of convection; the interpretation among the CRMs is more delicate. The same relationship is broadly reproduced by the SCMs, but with a much larger scatter (Fig. 15(d)). This reflects the larger variety of responses induced by the different sets of physical parametrizations involved. The large values of CAPE found in some SCMs can be directly linked to higher $\theta_{\mathrm{e}_{\mathrm{BL}}}$ values. In addition, in the evening, SCM-simulated $\theta_{\mathrm{e}_{\mathrm{BL}}}$ and CAPE do not reach values as low as in CRMs.

This simple link between $\theta_{\mathrm{e}_{\mathrm{BL}}}$ and CAPE results from more complex $\left(\theta_{\mathrm{BL}}, \mathrm{CAPE}\right)$ and $\left(q_{\mathrm{BL}}, \mathrm{CAPE}\right)$ relationships. In the CRMs, before noon, the CAPE increase is associated with the warming of the boundary layer (Fig. 15(b) and (c)). The early morning moistening of the boundary layer (until $\sim 1000 \mathrm{~h}$ ) also contributes to the CAPE increase in UKLEM and MésoNH. This is not the case for CRCP, because the boundary layer does not moisten in the early morning, as a result of its faster growth. This also explains why the CAPE maximum is lower in CRCP. Until $1600 \mathrm{~h}$, this difference can be attributed to specific humidity alone, as time-series of $\theta_{\mathrm{BL}}$ are extremely close among 

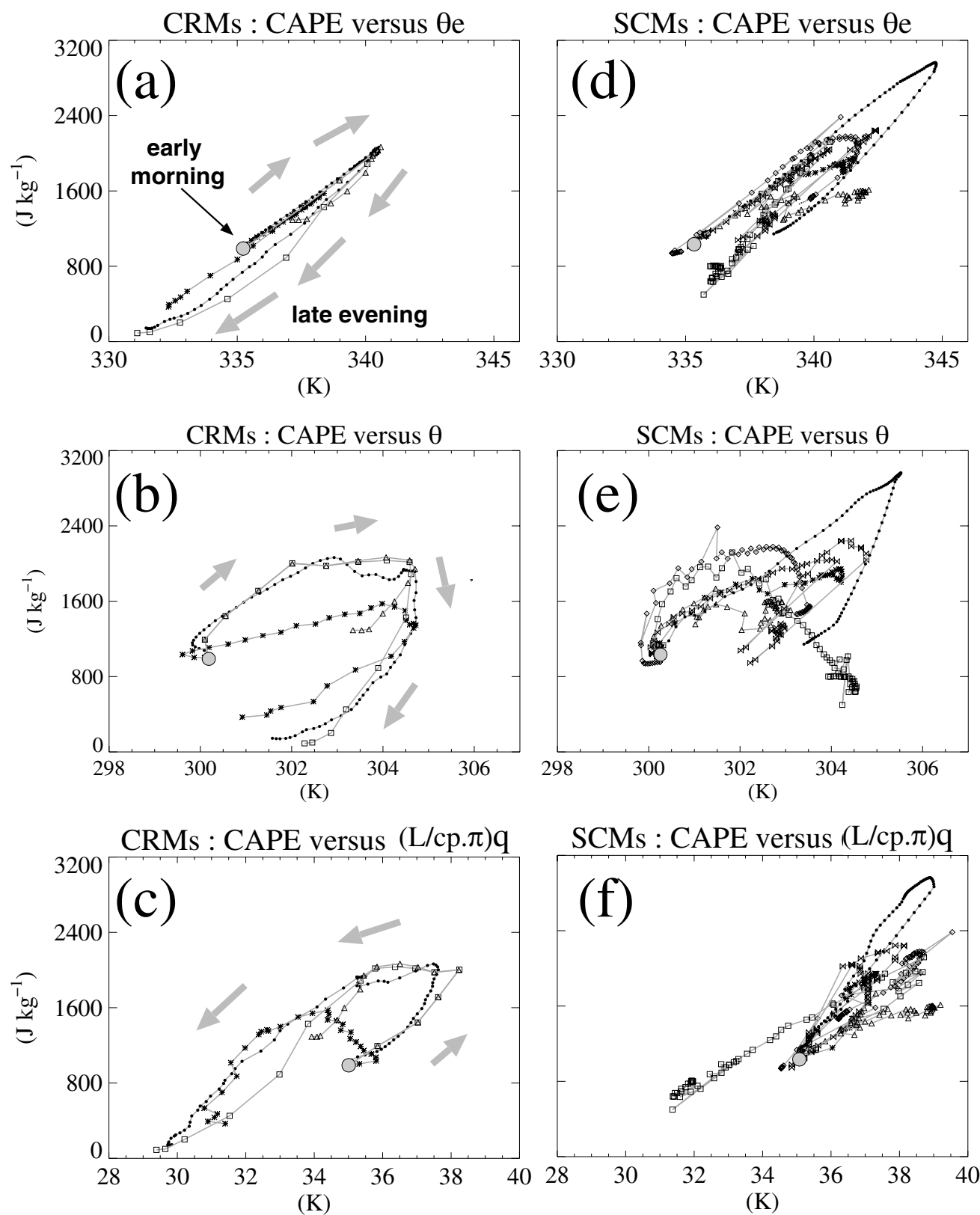

Figure 15. Scatter plots of convective available potential energy (CAPE) versus (a) the equivalent potential temperature $\theta_{e}$, (b) the potential temperature $\theta$, and (c) $\left(L / c_{p} \Pi\right) q$ in the boundary layer $(950 \mathrm{hPa})$ from the CRMs; (d), (e) and (f) as (a), (b) and (c), but from the SCMs. The time period covers $0500 \mathrm{~h}$ to $2300 \mathrm{~h}$ on the first day, each symbol standing for one model/simulation. The calculations have been performed for parcels originating from the same height $(950 \mathrm{hPa})$ after interpolation of the model output onto a common $5 \mathrm{hPa}$ resolution vertical grid. 
the CRMs. $\theta_{\mathrm{BL}}$ further increases until $\sim 1600 \mathrm{~h}$, while $q_{\mathrm{BL}}$ decreases from $\sim 1000 \mathrm{~h}$ until sunset. As previously stated, the scatter among the CRMs does not imply that one CRM is better or worse than another. However, despite these variations, a common picture emerges from this analysis.

In contrast, the SCMs exhibit various behaviours (Figs. 15(d) and (e)). The daytime variations of $\theta_{\mathrm{BL}}$ are broadly similar in some of them, but not those of $q_{\mathrm{BL}}$. In particular, the SCMs do not predict any drying of the boundary layer, except the ones which developed a high boundary layer, i.e. the ones that do not take into account convective downdraughts, which constitutes a paradoxical result.

The same analysis has been handled for CIN. The vertical grid of the SCMs (and the CRMs to a lesser extent) does not provide sufficient resolution for a proper prediction of small CIN, of the order of a few $\mathrm{J} \mathrm{kg}^{-1}$, as can be found towards noon. This does not preclude an investigation of the diurnal cycle of the CIN, though. Its range of diurnal variation is typically of the order of $100 \mathrm{~J} \mathrm{~kg}^{-1}$, i.e. a range that is large enough to be captured by the resolution of the models involved. In the CRMs, CIN, like CAPE, is largely controlled by variations of $\theta_{\mathrm{e}_{\mathrm{BL}}}$ (Fig. 16(a)). CIN typically decreases during the morning hours, then stays close to zero from $\sim 1000 \mathrm{~h}$ until $\sim 1500 \mathrm{~h}$. From there, it increases continuously and reaches its maximum after sunset. Again, this simple link results from more complex variations of $\theta_{\mathrm{BL}}$ and $q_{\mathrm{BL}}$ (Figs. 16 (b) and (c)); they are consistent among the CRMs, in particular on the $\left(\theta_{\mathrm{BL}}, \mathrm{CIN}\right)$ diagram.

A similar broad picture is given by the SCMs (Fig. 16(d)), but again the scatter is large among models. In particular, it appears that CIN decreases very rapidly and stays very close to zero from $\sim 0900 \mathrm{~h}$ until sunset in many models. Very low CIN associated with the large amounts of CAPE inevitably leads to the triggering of deep convection in many SCMs, simply by the design of the convection schemes. Furthermore, later on CIN does not reach values as high as in the CRMs, at first order because $\theta_{\mathrm{e}_{\mathrm{BL}}}$ does not decrease as much (Fig. 16(d)). This cannot simply be related to a different simulation of night-time conditions, as CIN increases in CRMs several hours before sunset, due to the intrusion of convective downdraughts in the boundary layer that bring dry evaporatively cooled air from upper layers.

This point is further explored with a diagram showing the variation of CIN $(\partial \mathrm{CIN} / \partial t)$ as a function of rainfall, the latter being used as a proxy for convective activity (Figs. 17(a) and (b)). Different behaviours can be seen between the CRMs and the SCMs. The occurrence of rainfall is clearly coupled to a significant increase of CIN in CRMs (all of the points except one are located above the axis $\partial \mathrm{CIN} / \partial t=0$ ). In addition, for a given CRM, the larger the afternoon rainfall, the larger the evening CIN will be. This is not the case in most SCMs, indeed most points stay close to $\partial \mathrm{CIN} / \partial t=0$ for non-zero rainfall rates, and the points departing the most from $\partial \mathrm{CIN} / \partial t=0$ are negative as a result of rainfall occurring in the morning in some models. HIRLAM-CLIM has a distinct behaviour. Large CIN increases follow convective events in this model, but they develop once the rainfall has stopped. This is why this feature does not appear on this diagram. In summary, CRM-simulated precipitating convection efficiently stabilizes the atmosphere by increasing CIN in the afternoon; this occurs via the transport by convective downdraughts of cool and dry air in the boundary layer. This pattern is not well reproduced by the SCMs. This finding suggests that parametrized models in such convective situations may underestimate the diurnal cycle of atmospheric stability.

A similar diagram showing how $\partial \mathrm{CAPE} / \partial t$ varies with rainfall also underlines basic differences between the SCMs and the CRMs (Figs. 17(c) and (d)). $\partial$ CAPE/ $\partial t$ involves large daytime variations of $\theta_{\mathrm{e}_{\mathrm{BL}}}$ that are more indirectly linked to moist convective activity. In the CRMs, variations of $\partial \mathrm{CAPE} / \partial t$ are negatively correlated with 

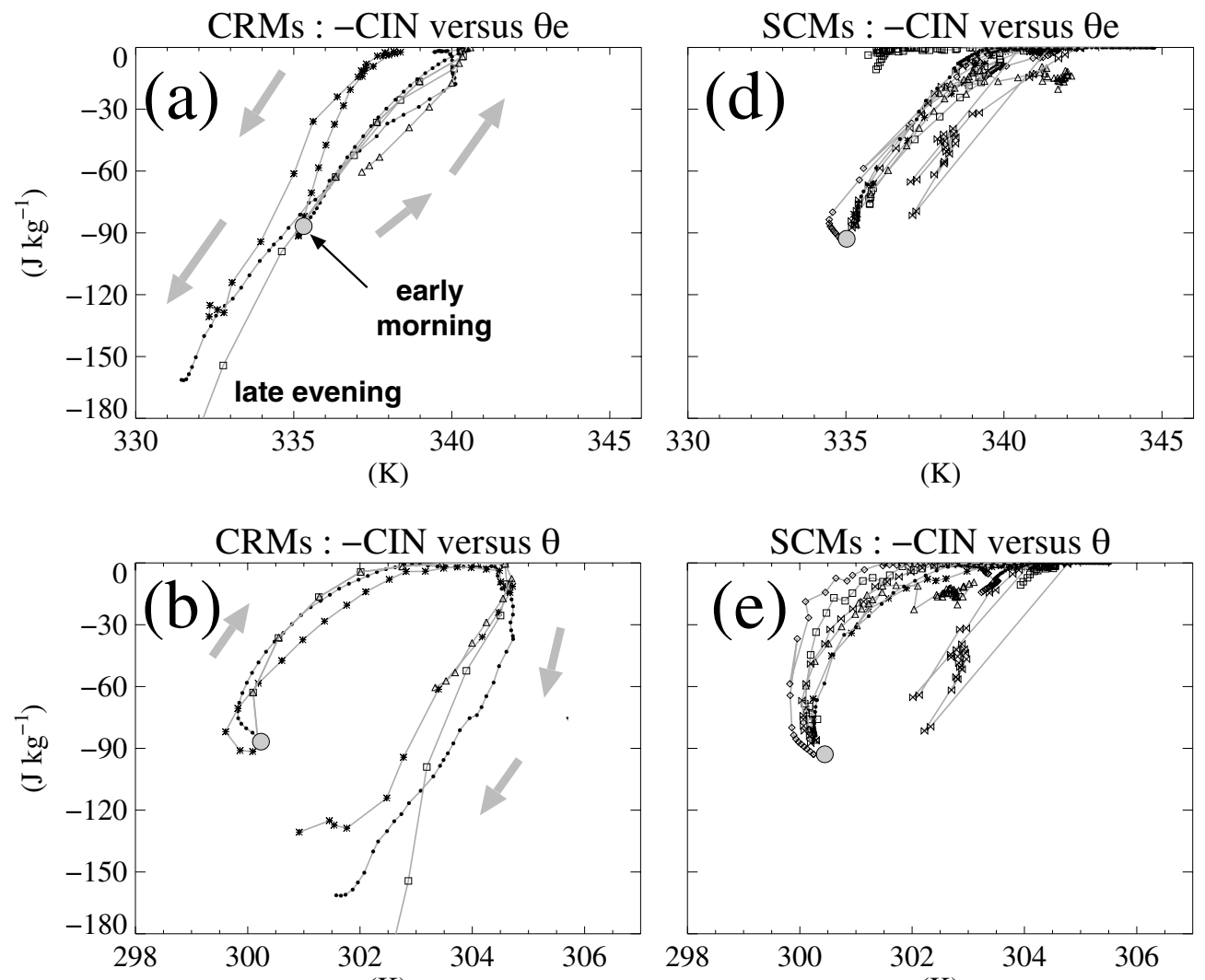

(K)

(K)
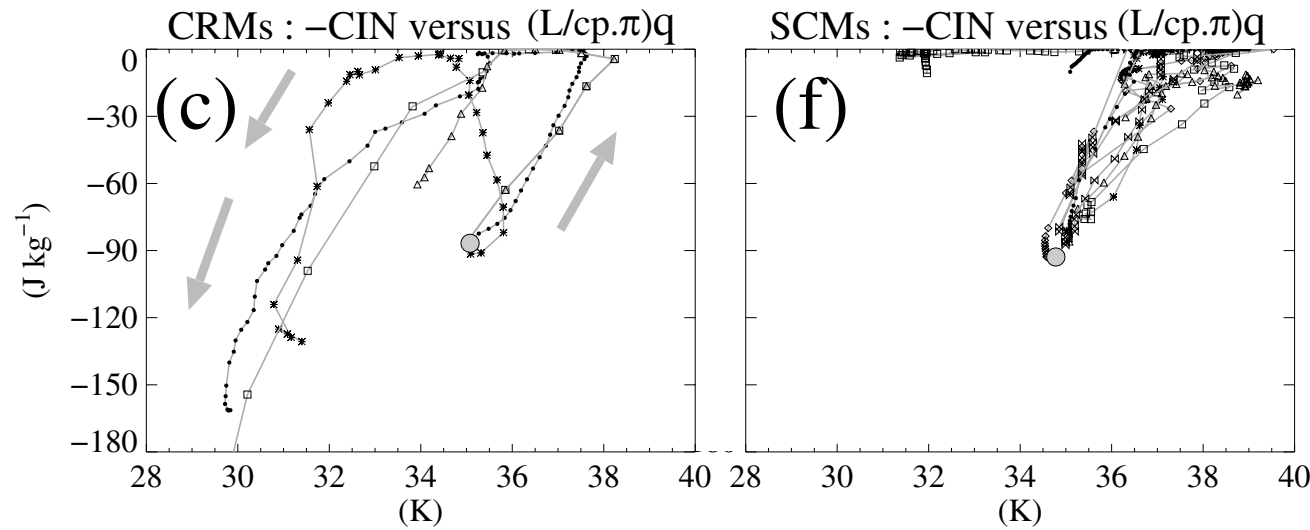

Figure 16. As Fig. 15, but for the convective inhibition (CIN). See text for further information.

rainfall. The large spread of values, towards the axis $\partial \mathrm{CAPE} / \partial t=0$ in the SCMs reflects the early timing of the rainfall, which is more in phase with the boundary-layer diurnal cycle.

It is tempting to relate this type of SCM behaviour to a failure of the quasiequilibrium (QE) hypothesis (Arakawa and Schubert 1974) when applied at subdiurnal timescales over land under conditions of weak forcing by large-scale advection, as in the present case (e.g. see Zhang (2002), hereafter referred to as Z02, and Donner 

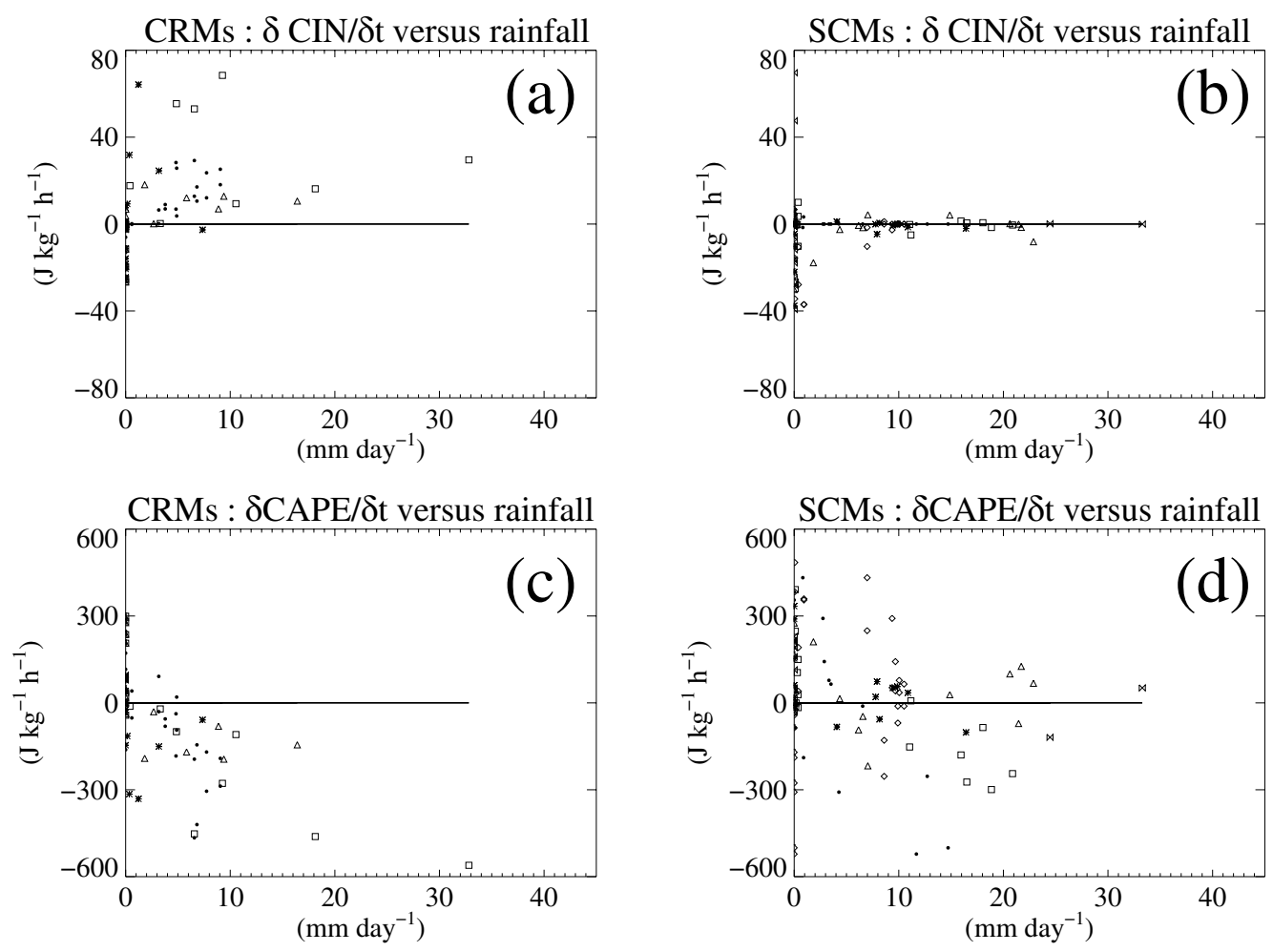

Figure 17. Scatter plots of the time variations of the convective inhibition (CIN) versus rainfall for (a) the CRMs and (b) the SCMs, from one-hour average values; (c) and (d) as (a) and (b), but for the time variations of the convective available potential energy (CAPE).

and Phillips (2003))*. In effect, this hypothesis, which relates the intensity of cumulus convection to the rate of destabilization induced by the other non-convective (usually referred to as 'large-scale') processes, has been implemented in most existing parametrizations of deep precipitating convection $\dagger$. In the present case, this parametrization responds to the large CAPE increase induced by surface and boundary-layer processes during the morning hours. However, as stressed by Randall et al. (1997), boundary-layer processes are not appropriately defined as a 'large-scale forcing'. Interestingly, Cripe and Randall (2001) (hereafter referred to as CR01) argued for the validity of the QE hypothesis on the basis of an analysis of datasets that were partly the same as in Z02all of them were derived from various ARM SGP IOPs. Note, however, that CR01 did not apply the same test as Z02 but proposed a new method to assess the QE assumption. They show that the actual values of the convective index GCAPE $\ddagger$ are much lower than they would be if the profiles of relative humidity were fixed, a result that supports the hypothesis of GCAPE quasi-equilibrium in a broader sense as explained below.

\footnotetext{
* Some previous analyses over land led to the opposite conclusion, for instance Grell et al. (1991). However, they focused on severe convective storms - see also Arakawa and Chen (1987)—while Z02 considered longer time-series that include a wider variety of simulations.

$\dagger$ Note that different closures are adopted for non-precipitating and precipitating cumulus in several SCMs, whilst Arakawa and Schubert (1974) proposed a more unified parametrization.

\$ Generalization of CAPE-an index related to CAPE.
} 

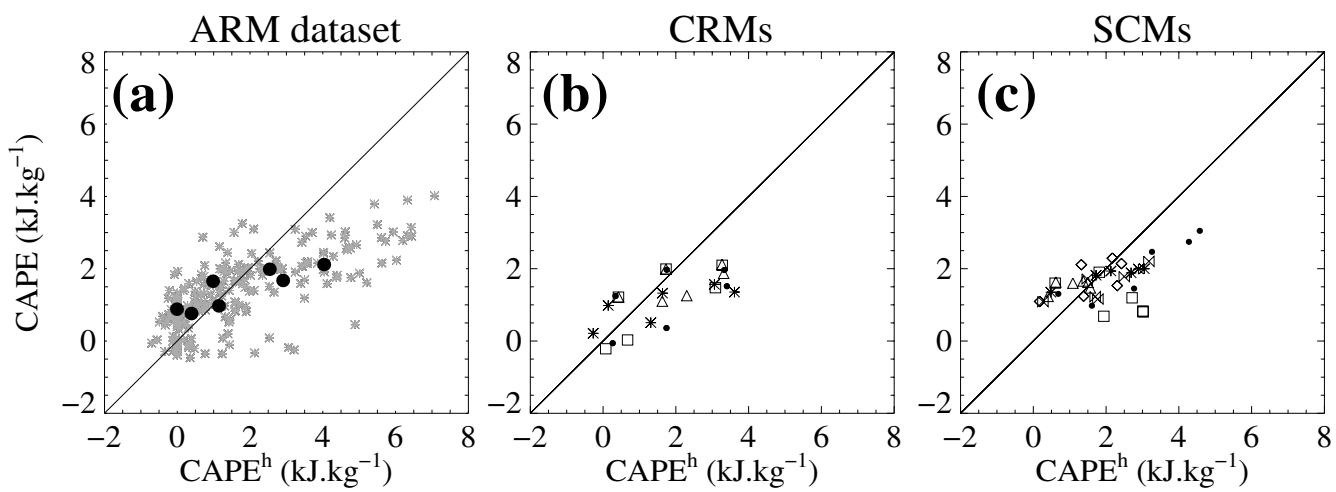

Figure 18. Scatter plots of three-hourly convective available potential energy (CAPE) versus the hypothetical CAPE, CAPE ${ }^{\text {h }}$ (see text), for (a) the ARM summer 1997 SCM IOP (b) the CRMs and (c) the SCMs. In (a) the black dots correspond to the data from 1200 UTC 27 June to 0600 UTC 28 June, i.e. the period shown in (b) and (c).

We investigated whether the CR01 result applied to our case-study of diurnal convection as follows. We compared the values of the actual CAPE and of a hypothetical CAPE, denoted CAPE ${ }^{\mathrm{h}}$, computed from the same temperature field $T$ but with the moisture field obtained from $T$ and the time-averaged vertical profile of relative humidity. When applied to the whole 1997 summer SCM ARM IOP (ARM analysis), it leads to Fig. 18(a), which shows that the CAPE does not reach as high values as $\mathrm{CAPE}^{\mathrm{h}}$, in agreement with CR01. The black disks in Fig. 18(a) indicate the values obtained for the period covered by this case-study. They lead to the same conclusion, as do our model results (Figs. 18(b) and (c)). We tested different values for the time-averaged relativehumidity profiles (e.g. we used the profiles from each model or from the ARM analysis for the actual period covered), but this did not change the general pattern. Usually, if one concentrates on one single day, $\mathrm{CAPE}^{\mathrm{h}}<\mathrm{CAPE}$ for the lower values of CAPE (predominantly during night-time), while CAPE ${ }^{\mathrm{h}}>\mathrm{CAPE}$ for the higher values of CAPE (predominantly during daytime), with a maximum of $\left|\mathrm{CAPE}^{\mathrm{h}}-\mathrm{CAPE}\right|$ towards noon. This characteristic underlines the contribution of the subdiurnal timescales to this relation. Interestingly, the same test applied to the CIN leads to the same conclusion, i.e. the CIN does not reach as high values as $\mathrm{CIN}^{\mathrm{h}}$. We also found some negative correlation between the low-level relative humidity and $\left(\Gamma-\Gamma_{\mathrm{m}}\right.$ ) (where $\Gamma$ and $\Gamma_{\mathrm{m}}$ are, respectively, the temperature and the moist-adiabatic temperature lapse rates), as expected from the $\mathrm{QE}$ assumption (see Arakawa and Chen 1987) but with some scatter, however, and distinct slopes in SCMs (not shown).

Therefore, while our results are broadly consistent with both views, they stress the need to clarify the treatment of the interactions between moist convection and the other processes in existing large-scale models. In effect, one of the reasons for the contrasting views of CR01 and Z02 lies in the different role that they implicitly give to boundary-layer processes. Z02 classifies boundary-layer processes as a 'largescale forcing' (which is a choice commonly adopted for the implementation of many existing cumulus parametrizations). Such a distinction is not required by the test of CR01. Indeed, the strong diurnal cycle of CAPE would be even stronger if turbulence (or dry convective motion) was not taking place in the daytime boundary layer. In this 
sense, boundary-layer convection acts to limit the values reached by the CAPE in the daytime hours*, but less efficiently than the subsequent precipitating convection.

As a closing remark, we did not attempt here to explore in detail the reasons for the particular signature of each model. However, we believe that this type of integrated diagnostics can be helpful for future testing of parametrizations and model intercomparisons, as they reveal in a synthetic way basic characteristics of the working of a given set of parametrizations.

\section{CONCLUSION}

The representation of the diurnal cycle of convection with NWP and climate models still remains a challenge. In the present study, a simple framework (case-study) has been designed in order to investigate this issue. This case can be used both by SCMs using parametrizations to represent moist convection and clouds, and by CRMs that explicitly simulate precipitating convective systems. The case-study was adapted from the GCSSARM WG4 Case 3, a multi-day case of continental convection (Xu et al. 2002; Xie et al. 2002). One day was selected from this case. It corresponds to the development of deep convection over land in summer, mainly forced by surface sensible- and latentheat fluxes. In practice, the first twelve hours of simulation, covering daytime, were instructive enough.

Within this simple framework, most of the seven SCMs involved in the study reproduced the same time shift as noted in full 3D large-scale models, with convective rainfall occurring too early within the course of the day. This occurred even though the 1D models predicted different daytime evolutions of the boundary layer and of atmospheric stability, in this situation characterized by large amounts of CAPE. The same case was simulated by three CRMs. In agreement with previous intercomparisons, more consistency was found among the CRMs than the SCMs. In addition, the CRMs did not predict any convective rain in the morning. The reasons for this basic difference were investigated through a comprehensive analysis of the diurnal evolution experienced by the boundary layer, moist convection and clouds. Our main findings are illustrated in Fig. 19.

Despite some variations, the CRMs all qualitatively reproduced the same scenario. The boundary-layer growth gave rise to the formation of shallow forced clouds in the late morning. Towards noon, the CIN decreased to almost zero, and the clouds began to deepen. However, a few hours were necessary before the deeper precipitating clouds could be seen. This phase was also characterized by a significant convective moistening of the free troposphere $\left(Q_{2}\right)$. It progressively reached higher levels, and preceded the maxima of $Q_{1}$. Indeed, additional tests showed that the duration of this growing phase of deep convection was sensitive to the moisture field. The occurrence of deep convection was accompanied by a large increase of CIN before sunset, linked to the penetration of dry cold convective downdraughts in the boundary layer. In the future, it would be especially useful (i) to analyse in-cloud values, which should help identify why the early clouds do not reach higher altitudes and (ii) to conduct comprehensive studies of the convective downdraughts' properties.

In most SCMs, it began to rain towards $0900-1000 \mathrm{~h}$, and the convective activity often lasted more or less intermittently until sunset, once $\theta_{\mathrm{e}_{\mathrm{BL}}}$ decreased sufficiently as a result of the stopping of surface heating. HIRLAM-CLIM was the only 'operational SCM' that did not predict convective rainfall in the morning. It is noticeable that the

\footnotetext{
* By vertically mixing the surface high $\theta_{\mathrm{e}}$ parcels with parcels from above characterized by a lower $\theta_{\mathrm{e}}$ (i.e. by generating a convective boundary layer).
} 

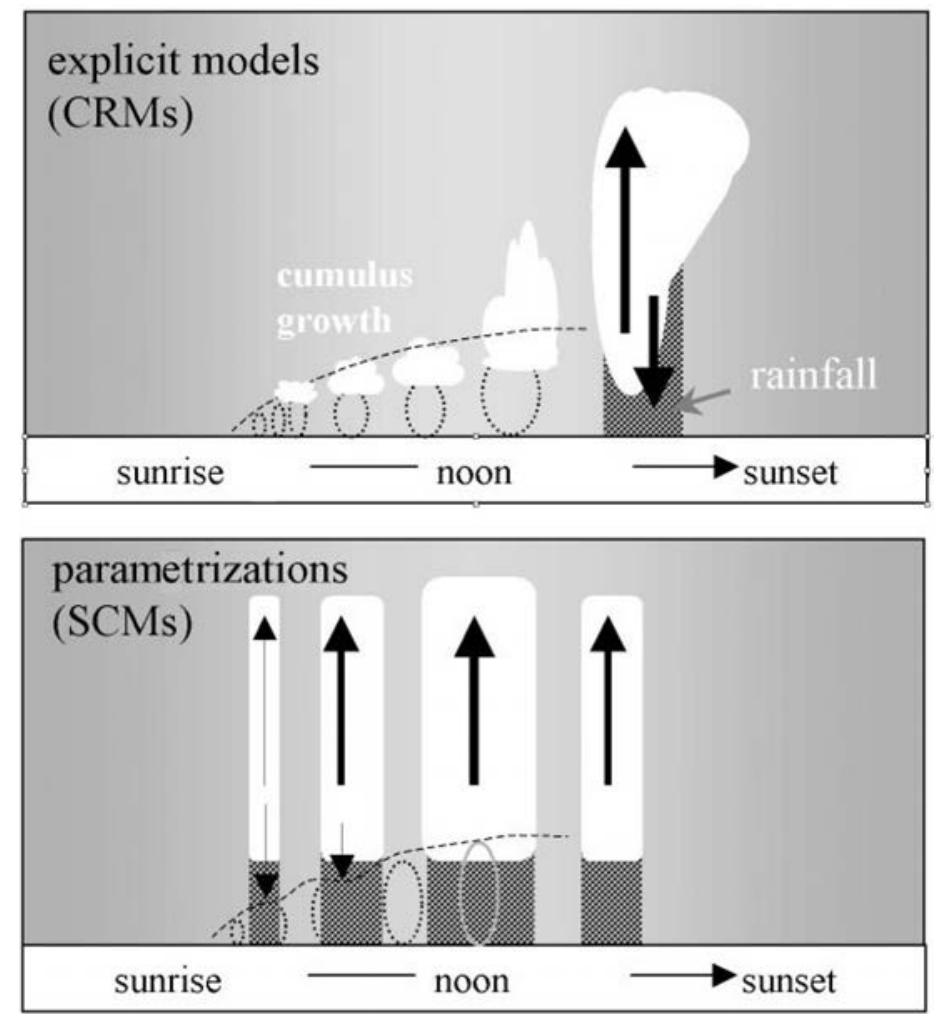

Figure 19. Schematic view of the diurnal cycle of precipitating convection, as simulated by the CRMs and several SCMs. The boundary-layer convection (thermals) is represented by the dotted curves on both schemes, as it partly relies on the turbulence in the CRMs with a two-kilometre horizontal resolution.

triggering criteria in this model differ from the ones used in most other schemes, indeed the timing of convection is quite sensitive to small changes in this trigger function, as has also been stressed by Jakob and Siebesma (2003). The progressive growth of convective clouds was only captured by PLUMES, a unified moist convection scheme, which is still a research SCM. Consistent with the occurrence of convective rainfall in the morning, several SCMs predicted an instantaneous growth of deep convective clouds whose tops reached the neutral buoyancy level within one time step. Thus, deficiencies of convection schemes cannot be resolved only by a choice of better criteria to activate deep convection. The problem involves representing a succession of regimes, from dry to moist non-precipitating to precipitating convection (see the analysis of Chaboureau et al. (2004)). All of them equally play a part in this complex transitory phenomenon; their representation involves an ensemble of parametrizations, and how they interact together. Concerning deep convection more precisely, one might expect improvements from (i) the introduction of triggering factors relying more on the boundary-layer convective activity than simply on low-level convective instability criteria, (ii) stronger sensitivity of convection to the moisture field, (iii) a better treatment of convective downdraughts, and (iv) the representation of the finite time of cloud development.

Finally, during the course of the project, specific limitations of the CRMs have been identified, in particular the sensitivity of the timing of precipitating convection to the resolution (Petch et al. 2002), and to the representation of subgrid-scale processes (e.g. the 
formulation of the mixing length in the turbulence scheme, and the parametrization of subgrid-scale microphysical processes). These choices affect the simulation of shallowcloud properties (e.g. their liquid-water path). Indeed, a $2 \mathrm{~km}$ horizontal resolution is not sufficient for an explicit simulation of the convective boundary layer (clear and cloudy), nor is the vertical resolution, on the order of $100 \mathrm{~m}$ in the entrainment zone. This resolution typically coincides with the scale of convective boundary-layer circulations which are, therefore, partly resolved and partly handled by the turbulence scheme. This issue has been addressed during the course of EUROCS (e.g. Petch et al. 2002). However, dedicated efforts are still needed in the future. The aim is not only to improve CRMs, but also to prepare for the next generation of NWP models, whose horizontal resolution will be on the order of $2 \mathrm{~km}$. It would be useful to assess CRM subgrid-scale parametrizations with the case studies of shallow convective clouds developed by the GCSS-WG1 group. The fair-weather cumulus case (Brown et al. 2002) is particularly well adapted for this purpose, in the context of the diurnal cycle of convection.

\section{ACKNOWLEDGEMENTS}

This study was made with the financial support of the European Union (contract number EVK2-CT-1999-00051). The first author was partly supported by the EUROCS project during the course of this work. We wish to acknowledge our colleagues (in particular C. Jakob) who participated in this project for a number of fruitful discussions during the workshops organized in Reading, Lisboa, De Bilt and Madrid. We also thank the reviewers for their careful review, the editor for his comments, A. Beljaars for his useful advice on surface fluxes, and J.-P. Lafore and J.-I. Yano for several discussions. Finally, editing of the manuscript by M. Doherty and K. Sandoval is acknowledged.

Arakawa, A. and Chen, J. M.

Arakawa, A. and Schubert, W. H.

Bechtold, P., Redelsperger, J.-L.,

Beau, I., Blackburn, M.,

Brinkop, S., Grandpeix, J.-Y.,

Grant, A., Gregory, D.,

Guichard, F., Hoff, C. and

Ioannidou, E.

Bechtold, P., Bazile, E.,

Guichard, F., Mascart, P. and

Richard, E.

Bechtold, P., Chaboureau, J.-P.,

Beljaars, A., Betts, A. K.,

Köhler, M., Miller, M. and

Redelsperger, J.-L.

Bergman, J. W. and Salby, M. L.

Betts, A. K. and Jakob, C.

\section{REFERENCES}

1987

1974

2000

2001

2004

1997

$2002 \mathrm{a}$
'Closure assumptions in the cumulus parameterization problem'. Pp. 107-131 in Short- and medium-range numerical prediction, Ed. T. Matsuno, WMO/IUGG NWP symposium, Tokyo. Meteorological Society, Tokyo, Japan

Interaction of a cumulus cloud ensemble with the large-scale environment, Part I. J. Atmos. Sci., 31, 674-701

A GCSS model intercomparison for a tropical squall line observed during TOGA-COARE. II: Intercomparison of single-column models and a cloud-resolving model. Q. J. R. Meteorol. Soc., 126, 865-888

A mass flux convection scheme for regional and global models. Q. J. R. Meteorol. Soc., 127, 869-886

The simulation of the diurnal cycle of convective precipitation over land in a global model. Q. J. R. Meteorol. Soc., 130, 3119-3137

The role of cloud diurnal variations in the time-mean energy budget. J. Climate, 10, 1114-1124

Evaluation of the diurnal cycle of precipitation, surface thermodynamics and surface fluxes in the ECMWF model using LBA data. J. Geophys. Res., 107(D20), 8045, doi: 10.1029/2001JD000427

2002 b Study of the diurnal cycle of convective precipitation over Amazonia using a single column model. J. Geophys. Res., 107(D20), 4732, doi: 10.1029/2002JD002264 
Betts, A. K., Fuentes, J. D.,

Garstang, M. and Ball, J. H.

Betts, A. K., Gatti, L. V.,

Cordova, A. M.

Silva Dias, M. A. F. and

Fuentes, J. D.

Bougeault, $\mathrm{P}$

Bougeault, P. and Lacarrère, P.

Brown, A. R., Cederwall, R. T.,

Chlond, A., Duynkerke, P. G.,

Golaz, J.-C.,

Khairoutdinov, M.,

Lewellen, D. C., Lock, A. P.,

Macvean, M. K.,

Moeng, C.-H.,

Neggers, R. A. J.,

Siebesma, A. P. and

Stevens, B.

Carbone, R. E., Tuttle, J. D., Ahijevych, D. A. and Trier, S. B.

Chaboureau, J.-P., Guichard, F., Redelsperger, J.-L. and Lafore, J.-P.

Cheinet, S.

Cripe, D. G. and Randall, D. A.

2001

Dai, A.

Dai, A., Del Genio, A. D. and Fung, I

Dai, A., Giorgi, F. and

Trenberth, K. E.

Derbyshire, S. H., Beau, I., Bechtold, P., Grandpeix, J.-Y., Piriou, J.-M.,

Redelsperger, J.-L. and

Soares, P. M. M.

Donner, L. J. and Phillips, V. T.

Duvel, J.-P.

Emanuel, K. A.

Garreaud, R. D. and Wallace, J. M.

Ghan, S., Randall, D., Xu, K-M, Cederwall, R., Cripe, D., Hack, J., Iacobellis, S., Klein, S., Krueger, S., Lohmann, U., Pedretti, J., Robock, A., Rotstayn, L., Somerville, R., Stenchikov, G., Sud, Y., Walker, G., Xie, S., Yio, J. and Zhang, M. 2002a Surface diurnal cycle and boundary layer structure over Rondonia during the rainy season. J. Geophys. Res., 107(D20), 8065, doi: 10.1029/2001JD000356

$2002 \mathrm{~b}$ Transport of ozone to the surface by convective downdrafts at night. J. Geophys. Res., 107(D20), 8046, doi: 10.1029/2000JD000158

1985 A simple parameterization of the large-scale effects of cumulus convection. Mon. Weather Rev., 113, 2108-2121

1989 Parameterization of orographic induced turbulence in a mesobetascale model. Mon. Weather Rev., 117, 1872-1890

2002 Large-eddy simulation of the diurnal cycle of shallow cumulus convection over land. Q. J. R. Meteorol. Soc., 128, 10751094

2002 Inferences of predictability associated with warm season precipitation episodes. J. Atmos. Sci., 59, 2033-2056

2004 The role of stability and moisture in the diurnal cycle of convection over land. Q. J. R. Meteorol. Soc., 130, 3105-3117

2003 A multiple mass-flux parameterization for the surface-generated convection. Part I: Dry plumes. J. Atmos. Sci., 60, 2313-2327

2004 A multiple mass-flux parametrization for the surface-generated convection. Part II: Cloudy cores. J. Atmos. Sci., 61, 10931113

Joint variations of temperature and water vapor over the midlatitude continents. Geophys. Res. Lett., 28(13), 2613-2616

1999 Recent change in the diurnal cycle of precipitation over the United States. Geophys. Res. Lett., 26, 341-344

1997 Clouds, precipitation, and temperature range. Nature, 386, 665666

1999 Observed and model simulated precipitation diurnal cycle over the contiguous United States. J. Geophys. Res., 104, 63776402

2004 Sensitivity of moist convection to environmental humidity. Q. J. R. Meteorol. Soc., 130, 3055-3079

2003 Boundary layer control on convective available potential energy: Implications for cumulus parameterization. J. Geophys. Res., 108(D22), doi: 10.1029/2003JD003773

1989 Convection over tropical Africa and the Atlantic Ocean during northern summer. Part I: Interannual and diurnal variations. Mon. Weather Rev., 117, 2782-2799

1991 A scheme for representing cumulus convection in large-scale models. J. Atmos. Sci., 48, 2313-2335

1997 The diurnal march of convective cloudiness over the Americas. Mon. Weather Rev., 125, 3157-3171

2000 An intercomparison of single column model simulations of summertime midlatitude continental convection. J. Geophys. Res., 105, 2091-2124 
Gibelin, A.-L. and Déqué, M.

Grabowski, W. and Smolarkiewicz, P. K.

Gregory, D. and Rowntree, P. R.

1990

Gregory, D., Morcrette, J.-J., Jakob, C., Beljaars, A. C. M. and Stockdale, T.

Grell, G., Kuo, Y. and Pasch, R. J.

IPCC

Jakob, C. and Siebesma, A. P.

2003

Jones, C. G., Willén, U., Ullerstig, A. and Hansson, U.

Kain, J. S. and Fritsch, J. M.

Krueger, S. K.

1997

Lafore, J.-P., Stein, J., Asensio, N., Bougeault, P., Ducrocq, V., Duron, J., Fischer, C., Hereil, P., Marcart, P., Pinty, J.-P., Redelsperger, J.-L., Richard, E. and Vila-Guerau de Arellano, J. Le Treut, H. and Li, Z.-X.

LeMone, M. A and Zipser, E. J.

1980

Lenderink, G., Siebesma, A. P., Cheinet, S., Irons, S., Jones, C. G., Marquet, P., Müller, F., Olmeda, D., Calvo, J., Sánchez, E. and Soares, P. M. M.

Liberti, G. L., Chéruy, F. and Desbois, M.

Lin, X., Randall, D. A. and Fowler, L. D.

Liu, C. and Moncrieff, M. W.

Machado, L. A. T., Laurent, H. and Lima, A. A.

Petch, J. C.

Petch, J. C., Brown, A. R. and Gray, M. E. B.

2004

1998

1991

2001

2000

1998

2002
Anthropogenic climate change over the Mediterranean region simulation by a global variable resolution model. Climate Dyn., 20, 327-339

CRCP: a Cloud Resolving Convection Parametrization for modeling the tropical convecting atmosphere. Physica D, 133, 171-178

A mass flux convection scheme with representation of cloud ensemble characteristics and stability-dependent closure. Mon. Weather Rev., 118, 1483-1506

Revision of convection, radiation and cloud schemes in the ECMWF integrated forecast system. Q. J. R. Meteorol. Soc., 126, 1685-1710

Semi-prognostic tests of cumulus parameterization schemes in the middle latitudes. Mon. Weather Rev., 119, 5-31

Third Assessment Report-Climate Change 2001: The scientific basis, Contribution of Working Group I. Eds. J. T. Houghton, Y. Ding, D. J. Griggs, M. Noguer, P. J. van der Linden and D. Xiaosu. Cambridge University Press, UK

A new sub-cloud model for mass-flux convection schemes: Influence on triggering, updraft properties and model climate. Mon. Weather Rev., 131, 2765-2778

The Rossby Centre regional atmospheric climate model: Model climatology and performance characteristics for the present climate over Europe. Ambio, 33, 199-210

1990 A one-dimensional entraining/detraining plume model and its application in convective parameterization. J. Atmos. Sci., 47, 2784-2802

A GCSS intercomparison of cloud-resolving models based on TOGA COARE observations. Pp 113-127 in Proceedings of the ECMWF/GCSS workshop on new insights and approaches to convective parametrization, European Centre for Medium-Range Weather Forecasts, Reading, UK

The Meso-NH atmospheric simulation system. Part 1: Adiabatic formulation and control simulations. Ann. Geophys., 16, 90-109

Sensitivity of an atmospheric general circulation model to prescribed SST changes: Feedback effects associated with the simulation of cloud optical properties. Climate Dyn., 5, 175187

Cumulonimbus vertical velocity events in GATE. Part 1: Diameter, intensity, and mass flux. J. Atmos. Sci., 37, 2444-2457

2004 The diurnal cycle of shallow cumulus clouds over land: A singlecolumn model intercomparison study. Q. J. R. Meteorol. Soc., 130, 3339-3364 WETAMC/LBA. J. Geophys. Res., 107(D20), 8064 doi: 10.1029/2001JD000338

The predictability of convection in cloud-resolving simulations over land. O. J. R. Meteorol. Soc., 130, 3173-3187

2002 The impact of horizontal resolution on convective development in simulations of the diurnal cycle over land. Q. J. R. Meteorol. Soc., 128, 2031-2044 
Piriou, J.-M., Bouyssel, F. and Bazile, E.

Pope, V. D., Gallani, M. L., Rowntree, P. R. and Stratton, R. A.

Randall, D, Pan, D.-M., Ding, P. and Cripe, D. G.

Redelsperger, J.-L. and Sommeria, G.

Redelsperger, J.-L., Brown, P. R. A., Guichard, F., Hoff, C., Kawasima, M., Lang, S., Montmerle, T., Nakamura, K., Saito, K., Seman, C., Tao, W. K. and Donner, L. J.

Redelsperger, J.-L., Parsons, D. and Guichard, F.

Rickenbach, T. M., Ferreira, R. N., Halverson, J. B., Herdies, D. L. and Silva Dias, M. A. F.

Royer, J.-F., Belamari, M., Céron, J.-P., Chaumat, L., Guérémy, J.-F., Piriou, C., Redelsperger, J.-L., and Tyteca, S.

Shutts, G. J. and Gray, M. E. B.

Swann, H

Tiedtke, M.

Troen, I. and Mahrt, L.

Wallace, J. M.

Wylie, D. P. and Woolf, H. M.

Xie, S., Xu, K.-M.,

Cederwall, R. T., Bechtold, P., Del Genio, A. D., Klein, S. A., Cripe, D. G., Ghan, S. J., Gregory, D., Iacobellis, S. F., Krueger, S. K., Lohmann, U., Petch, J. C., Randall, D. A., Rotstayn, L. D.,

Somerville, R. C. J.

Sud, Y. C., von Salzen, K., Walker, G. K.,Wolf, A., Yio, J. J., Zhang, G. J. and Zhang, $M$.

Xu, K.-M. and Krueger, S. K.
A numerical modelling study of the geostrophic adjustment process following deep convection. Q. J. R. Meteorol. Soc., 120, 1145-1178

1998 Sensitivity to the representation of precipitating ice in CRM simulations of deep convection. J. Atmos. Res., 53, 2354-2364

2001 Evaluation of the mass-flux approach to parametrizing deep convection. Q. J. R. Meteorol. Soc., 127, 1239-1260

1989 A comprehensive mass-flux scheme for cumulus parameterization in large-scale models. Mon. Weather Rev., 177, 1779-1800

1993 Representation of clouds in large-scale models. Mon. Weather Rev., 121, 3040-3061

1986 A simple model of the atmospheric boundary layer: Sensitivity to surface evaporation. Boundary-Layer Meteorol., 37, 129148

1975 Diurnal variations in precipitation and thunderstorm frequency over the conterminous United States. Mon. Weather Rev., 103, 406-419

2002 The diurnal cycle of upper-tropospheric clouds measured by GOAS-VAS and the ISCCP. Mon. Weather Rev., 130, 171179

2002 Intercomparison and evaluation of cumulus parameterizations under summertime midlatitude continental conditions. Q. J. R. Meteorol. Soc., 128, 1095-1136

1991 Evaluation of cloudiness parameterisations using a cumulus ensemble model. Mon. Weather Rev., 119, 342-367 
Xu, K-M and Randall, D. A.

Xu, K.-M., Cederwall, R. T., Donner, L. J., Guichard, F., Grabowski, W. W., Johnson, D. E.,

Khairoutdinov, M.

Krueger, S. K. L., Petch, J., C., Randall, D. A., Seman, C. J., Tao, W.-K., Xie, S. C.,

Yio, J. J. and Zhang, M.-H. Yang, G. Y. and Slingo, J. M.

Zhang, M.-H. and Lin, J. L.

Zhang, M.-H., Cederwall, R. T., Yio, J. J. and Xie, S. C.

Zhang, G. J.
Updraft and downdraft statistics of simulated tropical and midlatitude cumulus convection. J. Atmos. Sci., 58, 1630-1649

Impact of interactive radiative transfer on the macroscopic behavior of cumulus ensembles. Part II: Mechanisms for cloud-radiation interactions. J. Atmos. Sci., 52, 800-817

An intercomparison of cloud-resolving models with the ARM summer 1997 IOP data. Q. J. R. Meteorol. Soc., 128, 593624

The diurnal cycle in the tropics. Mon. Weather Rev., 129, 784-801

Constrained variational analysis of sounding data based on column-integrated budgets of mass, heat, moisture, and momentum: Approach and application to ARM measurements. J. Atmos. Sci., 54, 1503-1524

Objective analysis of ARM IOP data: Method, feature and sensitivity. Mon. Weather Rev., 129, 295-311

Convective quasi-equilibrium in midlatitude continental environment and its effect on convective parameterisation. J. Geophys. Res., 107(D14), doi:10.1029/2001JD001005 